ÉCOLE DE TECHNOLOGIE SUPÉRIEURE UNIVERSITÉ DU QUÉBEC

THESIS PRESENTED TO

ÉCOLE DE TECHNOLOGIE SUPÉRIEURE

IN PARTIAL FULFILLMENT OF THE REQUIREMENTS FOR A MASTER'S DEGREE IN ENGINEERING M.Eng.

BY

Bogdan Dumitru DANCILA

ALTITUDE OPTIMIZATION ALGORITHM FOR CRUISE, CONSTANT SPEED AND LEVEL FLIGHT SEGMENTS

MONTREAL, DECEMBER 15, 2011

CCopyright 2011 reserved by Bogdan Dumitru Dancila 
CCopyright reserved

It is forbidden to reproduce, save or share the content of this document either in whole or in parts. The reader who wishes to print or save this document on any media must first get the permission of the author. 


\section{BOARD OF EXAMINERS}

THIS THESIS HAS BEEN EVALUATED

BY THE FOLLOWING BOARD OF EXAMINERS:

Dr. Ruxandra Botez, Thesis Advisor

Automated Manufacturing Engineering at École de technologie supérieure

Dr. Guy Gauthier, President of the board of Examiners

Automated Manufacturing Engineering at École de technologie supérieure

Dr. Adrian Hiliuta, External Examiner

CMC ELECTRONICS - ESTERLINE

THIS THESIS WAS PRESENTED AND DEFENDED

BEFORE A BOARD OF EXAMINERS AND PUBLIC

ON DECEMBER 12, 2011

AT ÉCOLE DE TECHNOLOGIE SUPÉRIEURE 



\section{FOREWORD}

One of the main research and development objectives in the aeronautical industry consists in the development of innovative equipment and algorithms that contribute to improving the standards of economic efficiency and environmental protection. The Green Aviation Research and Development Network (GARDN), a Business-Led Network of Centers of Excellence (B-LNCE), regroups leading Canadian Aerospace Industry and Academic Research Centers. GARDN actively promotes and supports projects and collaborative research that address the environmental protection using green aircraft design.

Under GARDN auspices, the Research Laboratory in Active Controls, Avionics and Aeroservoelasticity (LARCASE), at Ecole de Technologie Superieure (ETS), and CMC Electronics-Esterline, are collaborating on a research project investigating new or improved cruise and descent trajectory optimization algorithms for the CMC Electronics-Esterline's Flight Management System.

In this thesis, an algorithm is proposed that determines the optimal altitude that minimizes the total costs for flying a constant speed, level flight, cruise segment. This algorithm is the subject of the present thesis. 



\section{AKNOWLEDGEMENTS}

Firstly, I would like to thank my supervisor, Professor Ruxandra Botez, for the opportunity to perform my research at the Research Laboratory in Active Controls, Avionics and Aeroservoelasticity (LARCASE), and for the opportunity to learn and work on interesting aviation research projects. I would also like to express my deepest appreciation for her mentorship as well as for academic and financial support throughout the Master's program.

I would also like to thank to Mr. Dominique Labour from CMC Electronics - Esterline for the excellent collaboration and for sharing his knowledge of practical aspects related to FMS algorithm implementation. Many thanks are due to Mr Dominique Labour, Mr Rex Hygate, Mr Daniel Guertin and Mr Claude Provencal for offering me the additional CMC Electronics - Esterline scholarship. This scholarship gave me more encouragement to pursue and finalize my Master thesis on the Green Aviation Research and Development Network (GARDN) project, thus providing many learning opportunities and a great professional experience.

Also, I would like to thank my LARCASE colleagues, Ms. N. Dumondel and Messrs. J. Dupont, R. Glumineau, J.Hemmerle, T. Klotz, B. Langlet, F. Millet, T. Salamah, S. Souleymane, and L. Tevoedjre, for their collaboration and important contribution to producing the FMS data needed for the algorithm validation.

A special thank to my family for their constant support throughout the duration of the Master's program. 



\title{
ALTITUDE OPTIMIZATION ALGORITHM FOR CRUISE, CONSTANT SPEED AND LEVEL FLIGHT SEGMENTS
}

\author{
Bogdan Dumitru DANCILA \\ RÉSUMÉ
}

Dans ce mémoire le développement d'un algorithme est présenté. Dans cet algorithme, nous déterminons l'altitude optimale pour un vol de croisière, à une vitesse et altitude constantes, sur un segment donné de la trajectoire de vol. Le critère d'optimisation correspond à la minimisation des couts totaux, et, si possible, de la consommation de combustible, pour parcourir le segment de croisière spécifié. Le but principal est de prouver le concept d'un algorithme, pour une fonctionnalité du FMS, informant les pilotes sur l'altitude de vol optimale pour le segment de croisière considéré.

L'algorithme a été développé en MATLAB, en utilisant une nouvelle méthode de calcul de la consommation de combustible pour les vols de croisière, à une vitesse et altitude constantes, en utilisant les données de performance de l'avion. Trois modèles d'avion ont été considérées, un pour lequel le modèle du vol de croisière prend en compte la position du centre de gravité, et deux modèles qui ne le font pas.

L'algorithme a été développé pour des conditions normales de vol, et il ne prend pas en compte les couts correspondent aux changements d'altitude, au début et à la fin du segment, requises pour atteindre l'altitude optimale et revenir à l'altitude de croisière initiale.

Les performances de l'algorithme ont été évaluées sur trois modèles d'avion - Airbus A310, Sukhoi RRJ et Lockheed L1011. Les données de validation ont été générées à partir des informations produites sur une plate-forme FMS de CMC Electronics - Esterline, qui utilise les mêmes modèles d'avion, et les mêmes données de performance, pour les mêmes conditions de vol

Mots-clés : Flight Management System, altitude optimale de croisière, cout minimal, consommation de combustible 



\title{
ALTITUDE OPTIMIZATION ALGORITHM FOR CRUISE, CONSTANT SPEED AND LEVEL FLIGHT SEGMENTS
}

\author{
Bogdan Dumitru DANCILA
}

\begin{abstract}
In this thesis, the development of an algorithm is presented. The algorithm determines the optimal cruise altitude for flying an aircraft at a constant speed and altitude on a given segment of the flight route. The optimization criteria corresponds to the minimization of the total costs, and, if possible, fuel consumption, associated with flying the cruise segment. The main objective is the development of a new algorithm, for a functionality of the FMS platform, that will display for the pilots the advisory information on a segment's cruise altitude yielding the minimal cost.

The algorithm, developed in MATLAB, is using a new method for computing the fuel burn, for the level flight cruise segments, based on the aircraft's performance data. Three aircraft models were considered, one whose cruise modeling uses the center of gravity position, and two that do not use the center of gravity position.

The algorithm was developed for normal flight conditions, and does not consider the costs associated with the initial and final changes of altitude, necessary to reach the optimal altitude and, at the end of the segment, needed to return to the initial cruise altitude.

Algorithm performances were evaluated on three aircraft models - Airbus A310, Sukhoi RRJ and Lockheed L1011. The validation data were generated based on the information produced on a CMC Electronics - Esterline FMS platform that used an identical aircraft model, and performance data, for identical flight conditions.
\end{abstract}

Keywords: Flight Management System, optimal cruise altitude, minimal cost, fuel burn. 



\section{TABLE OF CONTENTS}

Page

INTRODUCTION

\section{1}

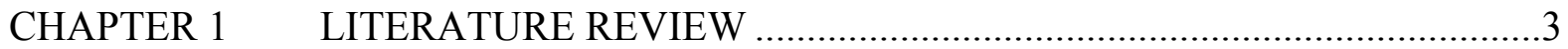

CHAPTER $2 \quad$ THEORETICAL ELEMENTS ….....................................................

2.1 The fuel burn rate model for constant speed, level, cruise flight............................... 7

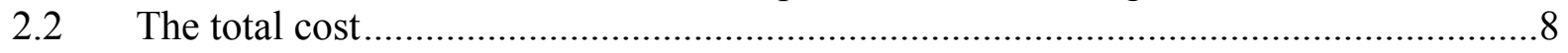

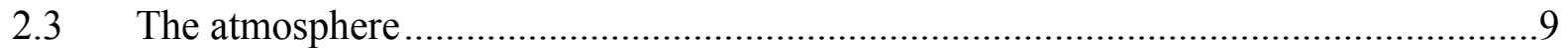

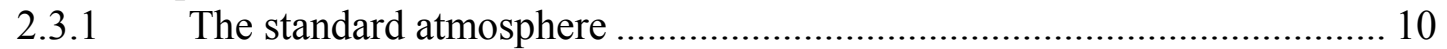

2.4 Mach number, IAS and TAS speeds. Crossover altitude........................................12

2.5 The flight segment and the wind structure..................................................... 14

2.6 Aircraft ground speed, wind triangle and segment flight time ...............................15

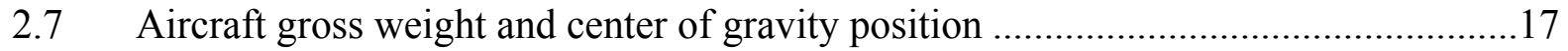

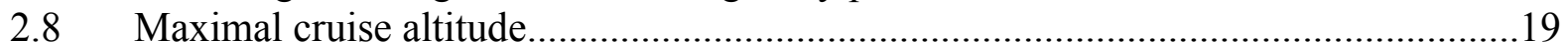

CHAPTER 3 ALGORITHM DEVELOPMENT …................................................21

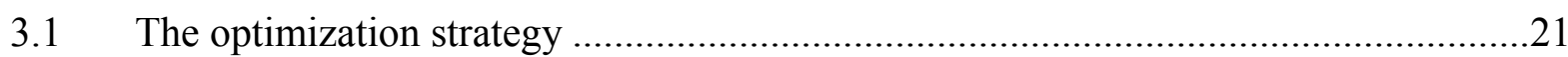

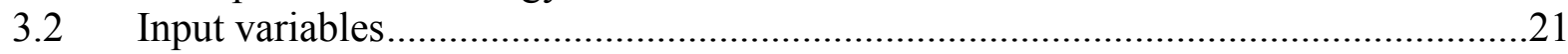

3.2.1 Optimization configuration parameters .......................................... 21

3.2.2 Aircraft design and performance data................................................ 22

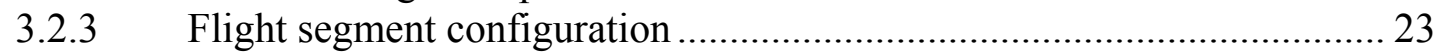

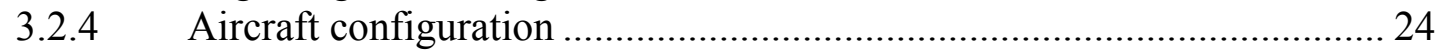

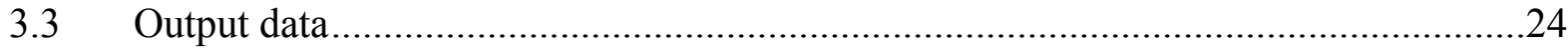

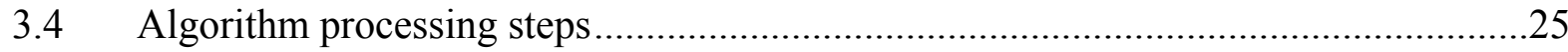

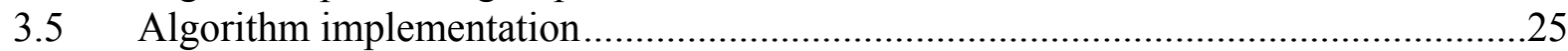

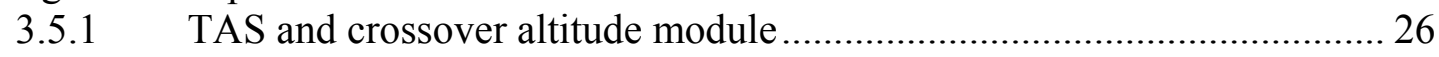

3.5.2 The maximal cruise altitude and cruise altitude range module................ 27

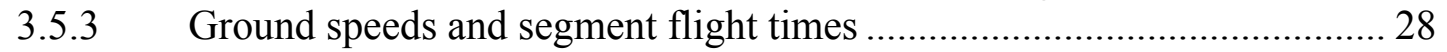

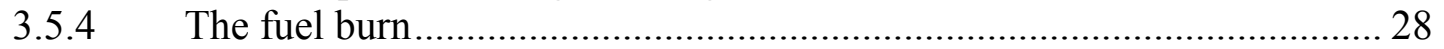

3.5.4.1 The initialization module ..................................................... 29

3.5.4.2 The intermediary module .................................................. 33

3.5.4.3 The fuel burn module........................................................ 37

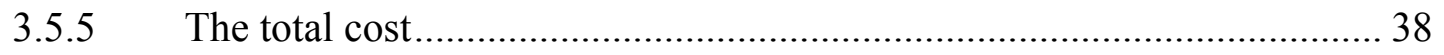

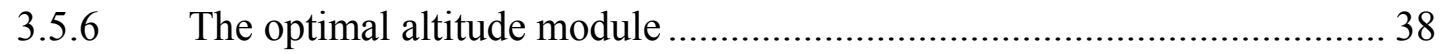

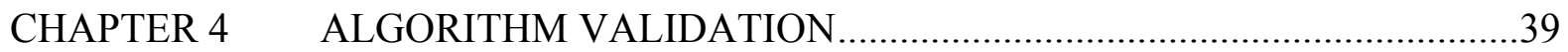

4.1 The test results for Airbus A310 ........................................................................43

4.2 The test results for Sukhoi RRJ ......................................................................51

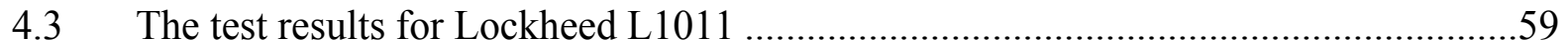

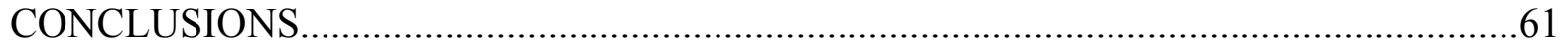


XIV

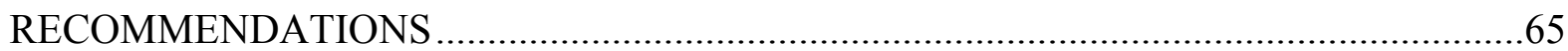

LIST OF BIBLIOGRAPHIC REFERENCES ........................................................67 


\section{LIST OF TABLES}

Page

Table 4-1

Description of the A310 test configurations .43

Table 4-2

A310 optimal altitude test results function of the cost index value

Table 4-3 A310 performance results, function of the cost index value, as a difference between the algorithm computed values at the optimal altitudes computed using the algorithm and the PTT validation data.

Table 4-4 A310 performance results, function of the cost index value, as the difference between the values computed using the algorithm and the PTT validation data, at the optimal altitude computed by the algorithm 46

Table 4-5

A310 Initialization module execution time statistics. . .48

Table 4-6

A310 Intermediary module execution time statistics.

Table 4-7

A310 Optimal altitude module execution time statistics .

Table 4-8

Description of the RRJ test configurations

Table 4-9

RRJ optimal altitude test results function of the cost index value..... .52

Table 4-10

RRJ performance results, function of the cost index value, as a difference between the algorithm computed values at the optimal altitudes computed using the algorithm and the PTT validation data..

Table 4-11 RRJ performance results, function of the cost index value, as the difference between the values computed using the algorithm and the PTT validation data, at the optimal altitude computed by the algorithm.

Table 4-12

RRJ Initialization module execution time statistics .56

Table 4-13

RRJ Intermediary module execution time statistics. .57

Table 4-14 RRJ Optimal altitude module execution time statistics . .57

Table 4-15 L1011 tests description and fuel burn results .60 



\section{LIST OF FIGURES}

Page

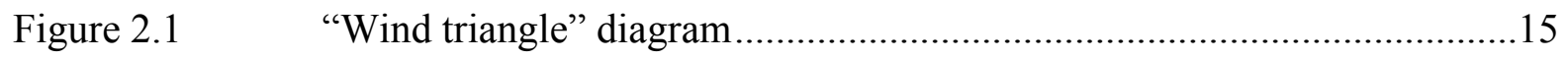

Figure 2.2 Aircraft weights and moments diagram ..........................................18 



\section{LIST OF ABBREVIATIONS AND ACRONYMS}

\begin{tabular}{|c|c|}
\hline A 310 & Airbus A310 \\
\hline $\mathrm{ADC}$ & air data computer \\
\hline B-LNCE & Bussiness-Led Network of Centers of Excellence \\
\hline CDA & Continuous Descent Arrivals \\
\hline ETS & Ecole de technologie superieure \\
\hline FMS & Flight Management System \\
\hline Flightsim & eNGENUITY Technologies Inc. - STAGE Flightsim 9.1 \\
\hline GARDN & Green Aviation Research and Development Network \\
\hline L1011 & Lockheed L1011 \\
\hline LARCASE & $\begin{array}{l}\text { Laboratory of Advanced Research in Control, Aerodynamics and } \\
\text { Aeroservoelasticity }\end{array}$ \\
\hline LNAV & Lateral Navigation \\
\hline MSL & Mean Sea Level \\
\hline OPD & Optimal Profile Descents \\
\hline PTT & CMC - Electronics Esterline CMA9000-PTT \\
\hline $\mathrm{RCL}$ & Recommended Cruise Level/Altitude \\
\hline RK4 & Runge-Kutta 4 numeric integration algorithm \\
\hline RNAV & Area Navigation \\
\hline RNP & Required Navigation Performance \\
\hline RRJ & Sukhoi Superjet 100 \\
\hline RTA & Requested Time of Arrival \\
\hline SI & International Standard of Units and Measurements \\
\hline
\end{tabular}


XX

VNAV

Vertical Navigation 


\section{LIST OF SYMBOLS AND MEASUREMENT UNITS}

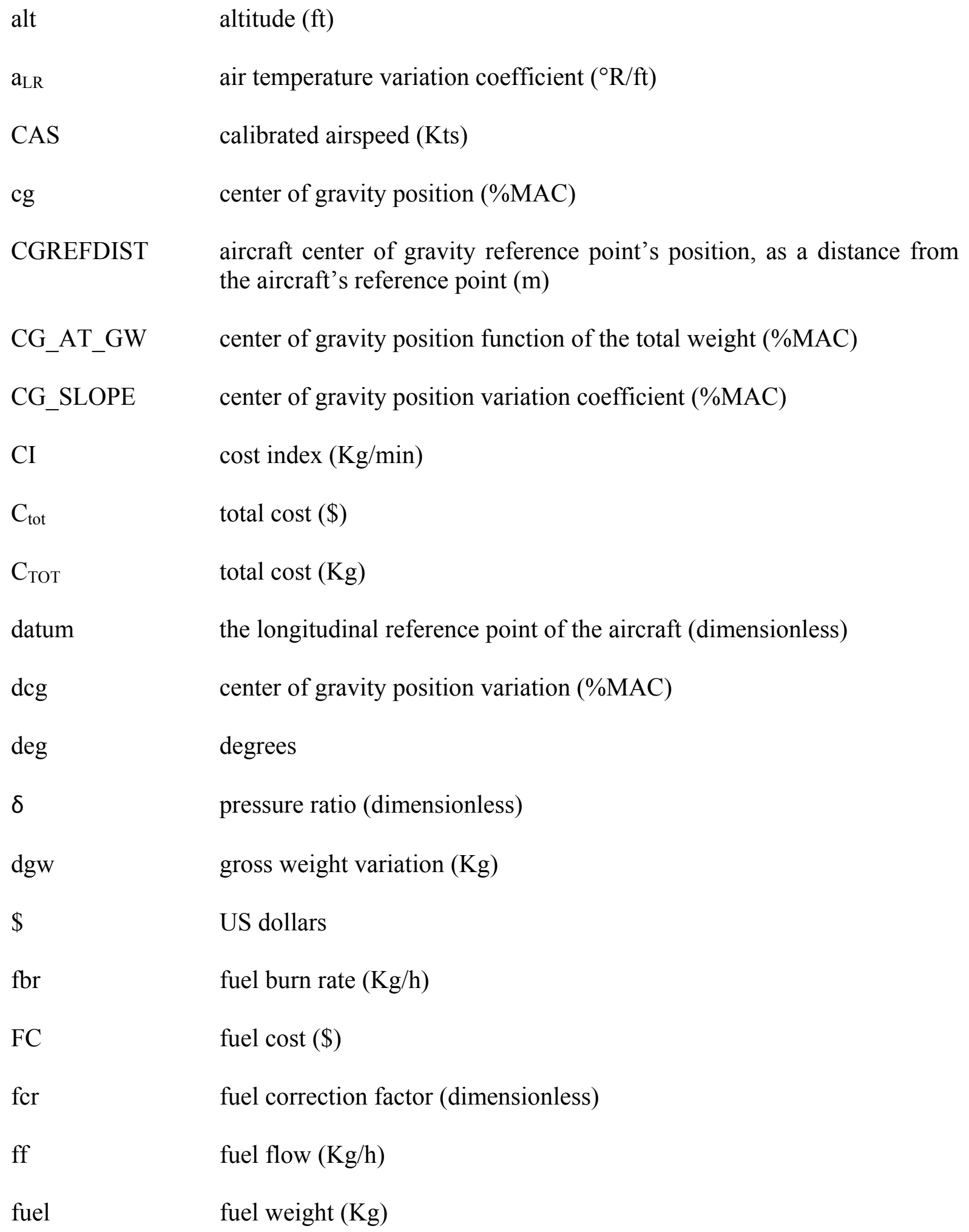




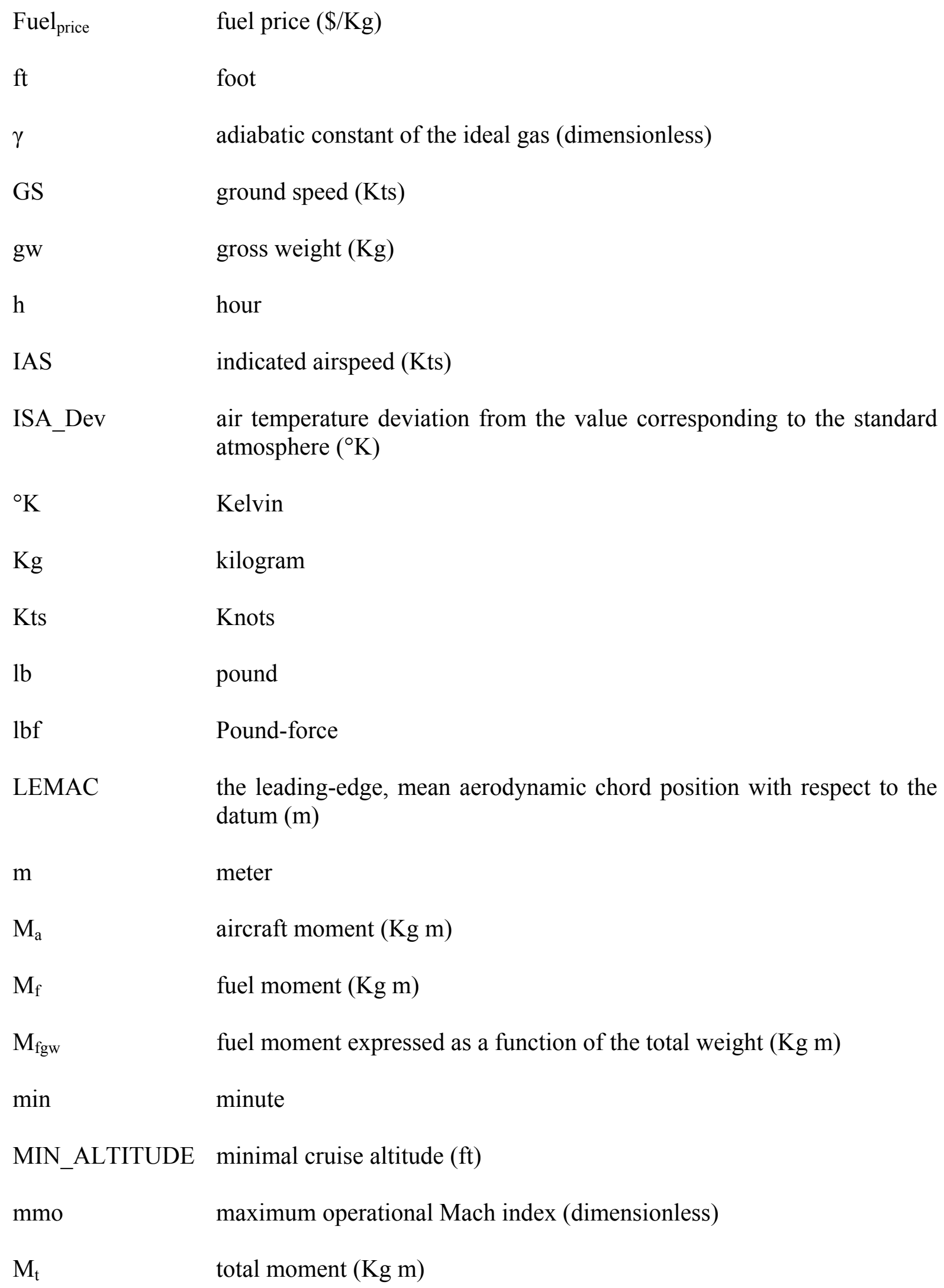




\begin{tabular}{|c|c|}
\hline MAC & Mean Aerodynamic Chord (m) \\
\hline$\% \mathrm{MAC}$ & percentage of MAC (dimensionless) \\
\hline Mach & Mach index (dimensionless) \\
\hline NFC & non fuel cost $(\$)$ \\
\hline $\mathrm{Nm}$ & nautical mile \\
\hline OAT & outside air temperature $\left({ }^{\circ} \mathrm{K}\right)$ \\
\hline OPT_DISTANCE & cruise segment length / optimization distance $(\mathrm{Nm})$ \\
\hline $\mathrm{p}$ & air pressure $\left(\mathrm{lb} / \mathrm{ft}^{2}\right)$ \\
\hline $\mathrm{p}_{\mathrm{SL}}$ & standard atmosphere, mean sea level air pressure $\left(\mathrm{lb} / \mathrm{ft}^{2}\right)$ \\
\hline $\mathrm{R}$ & ideal gas constant ( $\left.\mathrm{ft} \mathrm{lbf} / \mathrm{slug}{ }^{\circ} \mathrm{R}\right)$ \\
\hline${ }^{\circ} \mathrm{R}$ & Rankine \\
\hline$\rho$ & air density (slug/ $\left.\mathrm{ft}^{3}\right)$ \\
\hline$\rho_{\mathrm{SL}}$ & standard atmosphere, mean sea level air density $\left(\mathrm{slug} / \mathrm{ft}^{3}\right)$ \\
\hline slug & Slug - imperial weight unit \\
\hline$\sigma$ & density ratio (dimensionless) \\
\hline $\mathrm{T}$ & air temperature $\left({ }^{\circ} \mathrm{K}\right)$ \\
\hline $\mathrm{T}_{\mathrm{SL}}$ & standard atmosphere, mean sea level air temperature $\left({ }^{\circ} \mathrm{K}\right)$ \\
\hline $\mathrm{T}_{\text {flight }}$ & cruise segment' flight time (h) \\
\hline TAS & true air speed (Kts) \\
\hline temp & temperature $\left({ }^{\circ} \mathrm{K}\right)$ \\
\hline vmo & maximum operational IAS speed (Kts) \\
\hline WA & wind angle (deg) \\
\hline
\end{tabular}


XXIV

WCA wind correction angle, or crabbing angle (deg)

WV wind speed (Kts)

zfgw zero fuel gross weight $(\mathrm{Kg})$

zfwcg zero fuel weight center of gravity position (\%MAC) 


\section{INTRODUCTION}

The Flight Management System (FMS) is an important element of modern aviation. Its capabilities have a direct, and major, impact in terms of flight safety, environmental and economical performances. This thesis presents the development of an algorithm for a Flight Management System. This algorithm will determine the optimal cruise altitude for an aircraft flying on a given distance of its flight plan's cruise segment, at constant speed and altitude. The algorithm will yield the minimal total flight costs for the given flight distance.

A number of limitations were imposed in the development of the algorithm, which:

- Must be deterministic, meaning that at any time, an identical set of input parameters must conduct to an "identical" algorithm response.

- Must be compatible with the real-time nature of the FMS application. The modules requiring more time or processing resources must be executed as least as possible and should not affect the application's response time.

- Is compatible with the aircraft performance and capabilities description model, based on linear interpolation tables, used by the FMS platform.

- Is applicable to aircraft cruise performance description models as given by CMC Electronics that are dependent of the center of gravity position $(\mathrm{cg})$, and with models that are not.

The other limitations of the algorithm are:

- Only normal cruise operation conditions are considered. One engine operation or other abnormal conditions are not considered.

- The altitude optimization is performed for a cruise segment, defined by its heading and length.

- The cruise segment performances are evaluated at altitudes that are multiples of 1,000 ft. These altitudes are situated between a minimum altitude, provided as an algorithm input parameter, and aircraft's maximum attainable altitude, function of its performances, 
capabilities and its configuration (gross weight, center of gravity position, speed etc.) at the start of the segment.

- No time constraints were considered (such as Requested Time of Arrival, RTA, and arrival error cost function which factors the costs incurred for not observing the waypoints' arrival time constraints).

- At each altitude, the performances are evaluated for constant speeds.

- Aircraft speed is described by the speed schedule, defined by CMC Electronics as a couple of Indicated Air Speed (IAS) and Mach number (Mach) values. Their use is function of the crossover altitude, defined as the altitude at which the true air speed (TAS) computed using the $I A S$ equals the TAS computed using the Mach number. The $I A S$ value is used below crossover altitude, and the Mach value is used at or above crossover altitude.

- Two wind scenarios, associated with the cruise segment, are considered: still air (no wind), and constant wind. In the case of constant wind, the wind structure, describes the wind speed and direction at up to four altitudes, and is constant along the segment length.

- If a set of two or more altitudes yield the minimal cost, the selected optimal altitude corresponds to the altitude, in the set, also yielding the minimal quantity of burned fuel.

The first chapter reviews the current state of the art, related to the FMS and the cruise optimization algorithms. Subsequently, the second chapter details the main theoretical concepts used in the development of the algorithm. The third chapter presents the algorithm implementation for each of the two considered aircraft performance models. In chapter four, the results obtained with this algorithm are presented, and compared with the corresponding results, computed using the flight time and fuel burn information, generated on a PC-based FMS simulator. Finally, the conclusions and the recommendations for future work are presented. 


\section{CHAPTER 1}

\section{LITERATURE REVIEW}

The avionics industry has a continuous and special interest in augmenting the performances and capabilities of the FMS. This is determined by two factors: first, the introduction of new aviation standards and requirements; second, the ongoing increase in computing power and the development of new hardware and algorithms. An analysis of Liden [1] provides a comprehensive description of the development and evolution of the FMS, at Honeywell, since its initial design, in 1982. In a more recent work, Herndon et al. [2] describe some of the current key FMS concepts and directions of development, including Area Navigation (RNAV), Required Navigation Performance (RNP), Optimal Profile Descents (OPDs), and Continuous Descent Arrivals (CDA). A comparative analysis of the capabilities and performances of several modern FMS equipment is also provided.

As presented by Liden [1], two important sets of FMS functions, for performance prediction and for performance optimization, are used to compute flight trajectories that attain specific objectives (such as lateral navigation - LNAV, vertical navigation - VNAV, and cost or fuel burn optimization), while observing various constraints (such as speed, altitude, time or fuel burn). Past and current economic, and climatic, developments accentuated the interest for the development of new or improved FMS flight performance prediction and trajectory optimization algorithms and functions. One important class of performance optimization objectives refers to the determination of optimum cruise altitude profiles with the aim to minimize the flying costs incurred in flying a part of, or the entire cruise segment of the flight plan Liden [3]. The optimal cruise profile may consider time, as shown by Liden [4], or other

constraints, such as arrival error cost functions, see Liden [5]. The optimization process may be approached from different perspectives, such as energy-state equations Liden [5] and Shufan $\mathrm{Wu}$ et al. [6], or aircraft's performance and capabilities model, based on linear interpolation tables Liden [3]. 
The algorithm developed in the present thesis is based on the method that uses the aircraft's performance and capabilities model - described by Liden [3]. The computation of the optimal cruise altitude, also called the recommended cruise altitude (RCL), for a segment of a determined length, at constant speed, in level-flight conditions, was achieved by performing a series of forward predictions. The method described by Liden [3] determined the maximal altitude to use for the cruise segment, as a function of the current aircraft parameters (such as gross weight), selected speed and atmospheric conditions. Then the set of altitudes considered in the process of optimization were determined, by applying a set of restrictions imposed by the aircraft's performances and capabilities. For each altitude, the segment length was decomposed in intervals of up to $50 \mathrm{Nm}$, on which the ground speed, corresponding flight times, and fuel burns were computed. The fuel burn was computed using the fuel flow (ff) performance parameter, expressed in $\mathrm{kg} / \mathrm{h}$, as a function of the aircraft speed, gross weight $(g w)$, outside air temperature, and altitude. The fuel flow, considered constant on each interval, and equal to the value computed at the beginning of the interval, was integrated to produce the fuel burn. The cruise segment's total fuel burn and flight time, at each altitude, were computed as the sum of the fuel burns, and flight times respectively, of the corresponding intervals. Subsequently, the total cost, at each altitude was computed as the sum of the fuel cost, corresponding to the total fuel burn, and the non fuel cost. The non fuel cost was found to be proportional to the cruise segment's total flight time, by a factor called the Cost Index $(C I)$, expressed as the ratio between the price of one kilogram of fuel, and the non fuel cost for one minute of flight. Finally, the total cost values, corresponding to the set of altitudes, were compared and the altitude yielding the minimal total cost was selected as the optimal altitude.

The algorithm developed in this thesis, however, presents two main differences related to the constant speed, constant altitude, cruise, fuel flow modeling and fuel burn computation. It computes the instantaneous fuel consumptions, expressed in $\mathrm{kg} / \mathrm{h}$, called the fuel burn rates $(f b r)$, as a product between the fuel flow $(f f)$ and a new parameter, the fuel correction factor $(f c r)$. The fuel correction factor, expressed as a dimensionless value, allows a more flexible, aircraft cruise fuel burn modeling than the Liden's approach described in the previous 
paragraph. Two $f c r$ function models are considered, the first function considers the $f c r$ as a constant value, while the second function considers the $f c r$ as a function of the aircraft center of gravity position $(\mathrm{cg})$, speed, gross weight, and altitude. The algorithm also considers the continuous variation of the $f b r$ along the cruise flight segment, and computes the fuel burn as the integral value of the $f b r$ along the entire cruise segment length (flight time). Therefore, the value of the fuel burn, and the total cost, computed by the algorithm developed in this thesis are more accurate than the value computed considering a constant fuel burn rate, as described by Liden [3]. It also allows the computation of the fuel burn value for the entire cruise segment, without the constraint of decomposing it in sub-segments, irrespective of its length. 



\section{CHAPTER 2}

\section{THEORETICAL ELEMENTS}

The main theoretical concepts and elements used in the development of the algorithm are presented in this chapter. The cruise fuel burn model and the structure of the total flight cost are described in sections 2.1 and 2.2. The standard atmosphere and the relationship between the indicated air speed (IAS), Mach number (Mach), and the true air speed $(T A S)$ are presented in sections 2.3 and 2.4. The relationship between the aircraft's $T A S$, the wind, and the aircraft's ground speed is then presented in section 2.5 and 2.6. The method used to compute the position of the center of gravity of an aircraft is then described, in section 2.7 , and followed by the elements that determine the aircraft's maximal cruise altitude, in section 2.8 .

\subsection{The fuel burn rate model for constant speed, level, cruise flight}

The fuel burn rate $(f b r)$ model, employed in the present thesis, is obtained from the model that uses a fuel flow linear interpolation table, described by Liden [3], as a function of the aircraft's altitude, speed, outside air temperature and gross weight.

A new parameter, fuel correction factor $(f c r)$, that multiplies the fuel flow $(f f)$, allows a better characterization of the cruise flight. We considered two descriptions of the $f c r$, one as a constant value, and another as a linear interpolation table, as a function of the aircraft's speed, gross weight, center of gravity position, and altitude. Therefore, depending on the chosen fuel correction factor model, the equation describing the $f b r$ can have one of the following expressions:

$$
f b r(\text { speed }, g w, \text { temp }, \text { alt })=f f(\text { speed }, g w, \text { temp }, \text { alt }) * f c r
$$




$$
f b r(\text { speed }, g w, \text { temp }, \text { alt }, c g)=f f(\text { speed }, g w, \text { temp }, \text { alt }) * f c r(\text { speed }, g w, c g, \text { alt })
$$

The two equations describe the $f b r$ value at one specific moment in time $(t)$, for the corresponding set of input parameters: speed, gw, temp, alt, cg. However, the input parameters' values may constantly change during the flight. Therefore, it is appropriate to consider the $f f, f c r$, and $f b r$ as a function of time. Consequently, the equation describing the $f b r$ can also be written as follows:

$$
f b r(t)=f f(t) * f c r(t)
$$

\subsection{The total cost}

The cost model used in the present thesis, described by Liden [5] and Liden [3], computes the total cost $\left(C_{t o t}\right)$ associated with a flight as a sum of two factors: fuel cost $(F C)$, and non-fuel operational cost $(N F C)$.

$$
C_{\text {tot }}=F C+N F C
$$

The fuel cost is the price, in dollars, of the quantity of fuel burned $(F B)$ on the considered flight. It is computed as the product between the price of a kilogram of fuel (Fuel price) and the integral sum of the fuel burn rate $(f b r)$ over the entire segment distance. The non-fuel operational cost factor represents the sum of all non-fuel costs incurred for flying the considered trajectory. As described by Liden [3], its value, in dollars, is computed as the product between the segment flight time $\left(T_{\text {flight }}\right)$ and a cost index $(C I)$. The cost index is a parameter, whose value is established by the airline company, representing the non-fuel operational cost, expressed in kilograms of fuel, for a minute of flight. Usually, the duration of the flight is expressed in hours. Therefore, using equation (2.3) that considers the $f b r$ as a function of time, the total cost, expressed in dollars, is described by the equation: 


$$
C_{\text {tot }}=\text { Fuel }_{\text {price }} *\left(\int_{0}^{T_{\text {dight }}} f b r(t) * d t+60 * C I * T_{\text {flight }}\right)
$$

The total cost can be expressed independently of the price of fuel, by eliminating the Fuel $_{\text {price }}$ factor. Consequently, the equation describing the total cost, expressed in kilograms of fuel, becomes:

$$
C_{\text {TOT }}=\int_{0}^{T_{\text {fipight }}} f b r(t) * d t+60 * C I^{*} T_{f l i g h t}
$$

\subsection{The atmosphere}

Aerodynamic lift is one of the fundamental flight elements. It is produced by the relative motion between an airfoil and its surrounding mass of air (atmosphere), measured as the airspeed. Consequently, accurate measurement of the airspeed is essential for maintaining a stable, controlled flight. Therefore, it is important to have a good understanding and characterization of the atmosphere, and its parameters. The atmosphere parameters that characterize the unit volume of air are the pressure $(p)$, density $(\rho)$ and temperature $(T)$. The pressure can correspond to the static pressure $\left(p_{s}\right)$, determined by the weight of the air column situated above the measure point, the impact (or dynamic) pressure $\left(q_{c}\right)$ corresponding to the kinetic energy of the moving mass of air, and the total pressure $\left(p_{T}\right)$, as the sum of the static and dynamic pressures. These pressures can be expressed in SI (metric) or English units.

The variation of the air pressure, density and temperature is described by the equation of the ideal gas, as indicated by Aselin [7], Botez [8], and by other authors in the classical references:

$$
p=\rho R T
$$


Where $R$, the gas constant, is equal to $287 \mathrm{~J} / \mathrm{kg}{ }^{\circ} \mathrm{K}$ or $1716 \mathrm{ft} \mathrm{lbf} \mathrm{/} \mathrm{slug}{ }^{\circ} \mathrm{R}$ As atmospheric parameters change with time and location, it is also important to define aircraft performances with respect to a set of known, stable, atmospheric parameters values, called the standard atmosphere. It is thus possible to determine, and compare, aircraft performances in different atmospheric conditions.

\subsubsection{The standard atmosphere}

The standard atmosphere defines the proprieties of the atmosphere at a reference altitude, the mean sea level (MSL), where the air is dry, and behaves as an ideal gas. The reference values of the atmosphere parameters are defined and presented in the literature, such as Asselin [7] and Botez [8], for various sets of metric, and English, units.

For the range of altitudes corresponding to a normal flight, up to $21,000 \mathrm{~m}=21 \mathrm{Km}$, the atmosphere is composed of two layers: the troposphere, from 0 to $11 \mathrm{Km}=36,089 \mathrm{ft}$, where the temperature decreases linearly with the altitude, and the stratosphere, between $11 \mathrm{Km}=$ $36,089 \mathrm{ft}$ and $21 \mathrm{Km}=70,000 \mathrm{ft}$, where the temperature is constant. The air pressure and its density decrease with the altitude. The law of variation, for each of the parameters, is dependent on the atmosphere layer for which their values are computed, troposphere or stratosphere. In troposphere, the variation of the parameters, as described by Asselin [7] and Botez [8], is as follows: The temperature variation, with the altitude, is governed by the following equation:

$$
T_{h}=T_{S L}+a_{L R} h
$$

(Asselin [7], page 312)

where $a_{L R}$ is the temperature variation coefficient, which is $-0.0065^{\circ} \mathrm{K} / \mathrm{m}$ or $-0.00356^{\circ} \mathrm{R} / \mathrm{ft}$. The pressure variation with the altitude is described by the equation: 


$$
p_{h}=p_{S L}\left(\frac{T_{h}}{T_{S L}}\right)^{\left(-g / a_{L R} R\right)}
$$

(Asselin, [7], page 312)

The density variation with the altitude is described by the equation:

$$
\rho_{h}=\rho_{S L}\left(\frac{T_{h}}{T_{S L}}\right)^{\left(-1-g / a_{L R} R\right)}
$$

(Asselin, [7], page 313)

In stratosphere, as described by Botez [8], due to the fact that the temperature is constant, the pressure and density laws of variation are defined by the equations:

$$
\begin{aligned}
& p=p_{0 \text { strat }} e^{-\frac{g \Delta h_{\text {strat }}}{R T_{\text {strat }}}} \\
& \rho=\rho_{0 \text { strat }} e^{-\frac{g \Delta h_{\text {strat }}}{R T_{\text {strat }}}}
\end{aligned}
$$

where $T_{\text {strat }}$ is the stratosphere temperature $\left(216.66^{\circ} \mathrm{K},-56.5^{\circ} \mathrm{C}\right.$, or $\left.390^{\circ} \mathrm{R}\right), p_{0 \text { strat }}$ and $\rho_{0 \text { strat }}$ are the pressure and the density, at the initial stratosphere altitude of $11 \mathrm{Km}$, and $\Delta h_{\text {strat }}$ is the altitude measured with respect to the initial stratosphere altitude.

It is often useful to compare aircraft performances, or atmosphere parameters, at different altitudes, in the simplest way possible. The comparisons can be achieved by defining a set of parameters: temperature ratio $(\theta)$, pressure ratio $(\delta)$, and density ratio $(\sigma)$. As described by 
Asselin [7] and Botez [8], their values are computed, for any given altitude $h$, by dividing the value of the corresponding parameter at altitude $h$, by its, standard value at the MSL.

Another important parameter is the speed of sound (a), which is computed, as described by Asselin [7], Botez [8] and by other authors in the classical references, using the equation:

$$
a=\sqrt{\gamma R T}
$$

where $\gamma=1.4$ is the adiabatic constant of the ideal gas.

The atmospheric temperature, pressure, density, or their corresponding ratios, along with the speed of sound variations with the altitude, are summarized in the literature, such as Asselin [7] and Botez [8], as a standard atmosphere definition table.

In reality, the pressure, density and temperature values at the MSL are different than those defined for the standard atmosphere. One parameter, the temperature, is used to compute many aircraft performance data, including the fuel burn and the maximal altitude. The temperature difference with respect to the MSL is defined with respect to the standard atmosphere temperature. This parameter, called standard temperature deviation (ISA_Dev), provides a proper way of characterizing aircraft performances as a function of atmosphere variation.

\subsection{Mach number, IAS and TAS speeds. Crossover altitude}

On-board aircraft sensors, pitot-tubes and static pressure probes, measure the total pressure representing the sum of the static and the impact pressure, and the static atmospheric pressure, respectively. This information is processed by the air data computer (ADC), to produce three speed parameters: the indicated air speed (IAS), the Mach number (Mach), and the true air speed $(T A S)$. 
For the standard atmosphere, and compressible flow regions, the TAS is computed based on the dynamic and static pressures measured by the pitot-tube, using the equation:

$$
T A S=\sqrt{\left(\frac{2 \gamma}{\gamma-1}\right)\left(\frac{p}{\rho}\right)\left(\left[\left(1+\frac{p_{0}-p}{p}\right)^{\frac{(\gamma-1)}{\gamma}}-1\right]\right)}
$$

(Asselin, [7], page 323)

The $I A S$ value actually represents the value of the calibrated airspeed $(C A S)$, measured by the airspeed indicator. This value is equal to the TAS only at the sea level, for the standard atmosphere conditions. As described by Botez [8], the $T A S$ for a given altitude is obtained from the $I A S$, by compensating for the density and pressure variation with altitude. First, the differential pressure, $q_{c}$, corresponding to sea level, standard atmosphere conditions, is computed from the $I A S$ value using the equation:

$$
q_{c}=p_{0}-p=p_{S L}\left[\left(I A S^{2} \frac{\gamma-1}{2 \gamma} \frac{\rho_{S L}}{p_{S L}}+1\right)^{\frac{\gamma}{(\gamma-1)}}-1\right]
$$

which is obtained from the equation (2.14). Then, the pressure $(p)$, and density $(\rho)$, at the considered altitude are expressed as a function of the standard atmosphere, sea level values, and the pressure ratio $(\delta)$ and density ratio $(\sigma)$ corresponding to that altitude. Finally, they are replaced in equation (2.14), and the final form of the equation that computes the TAS is obtained:

$$
T A S=\sqrt{\left(\frac{2 \gamma}{\gamma-1}\right)\left(\frac{p_{S L}}{\rho_{S L}}\right)\left(\frac{\delta}{\sigma}\right)\left[\left(1+\frac{q_{c}}{p_{S L} \delta}\right)^{\frac{\gamma-1}{\gamma}}-1\right]}
$$


The $T A S$ value corresponding to a given Mach number is computed, as indicated by Asselin [7] and Botez [8], using the equation:

$$
\operatorname{TAS}(h)=\operatorname{Mach}^{*} a(h)
$$

where $a(h)$ represents the speed of sound at the altitude for which the TAS is computed.

For a speed schedule composed of a Mach number and an IAS speed, the crossover altitude is the altitude at which the $T A S$ value computed using the Mach number equals the $T A S$ value computed using the $I A S$ speed. Below the crossover altitude, the aircraft operation and parameters are referred to the $I A S$ speed. At and above the crossover altitude, the aircraft operation and parameters are referred to the Mach number.

\subsection{The flight segment and the wind structure}

The FMS performs the navigation and performance predictions, and guides the aircraft according to the flight plan entered by the pilots as a series of waypoints and airways. The waypoints are usually selected from the FMS' navigation database. The waypoints can also be entered manually using their geographic coordinates, or positions (distances, angles, or both) relative to one or two waypoints or navigation aid systems. Once the waypoints selected, the FMS computes the length and the heading of each of the segments determined by two consecutive waypoints.

Each waypoint may have a number of parameters, and restrictions, that apply to the segment starting at that waypoint. They may refer to altitude, speed schedule (IAS, Mach, or both), wind structure, standard temperature deviation (ISA_Dev), Requested Arrival Times, etc. If the segment speed schedule is configured as a pair of $I A S$ and Mach values, the $I A S$ value is used below, while the Mach value is used at and above the crossover altitude. The wind structure defines the wind layers, as the direction from which they blow, relative to the North, and their speeds, in Knots. Modern FMS, as described by Liden [1], can associate to 
each waypoint a structure characterizing the winds at up to four altitudes. At any altitude, the wind is computed through interpolation, using the values shown in the wind structure table. For the scope of the present thesis, we only consider the parameters that describe the segment length, heading, speed schedule, wind structure, and ISA_Dev.

\subsection{Aircraft ground speed, wind triangle and segment flight time}

The aircraft speed is measured with respect to the mass of air in which it flies. In still air conditions, aircraft's ground speed $(G S)$ is equal to the $T A S$. If the mass of air is moving, relative to the ground, the aircraft's ground speed is different than the $T A S$, and corresponds to the vector summation of the $T A S$ and wind speed $(W V)$. An aircraft is required to closely follow the segment's trajectory therefore, the angle of the resulting ground speed, relative to the North, must closely match the segment heading. To achieve that, the aircraft must compensate by changing its heading with an angle, called wind compensation angle $(W C A)$ or crabbing angle, which is dependent of the aircraft $T A S$, wind speed, and the relative angle between the segment heading and wind direction, called wind angle $(W A)$.

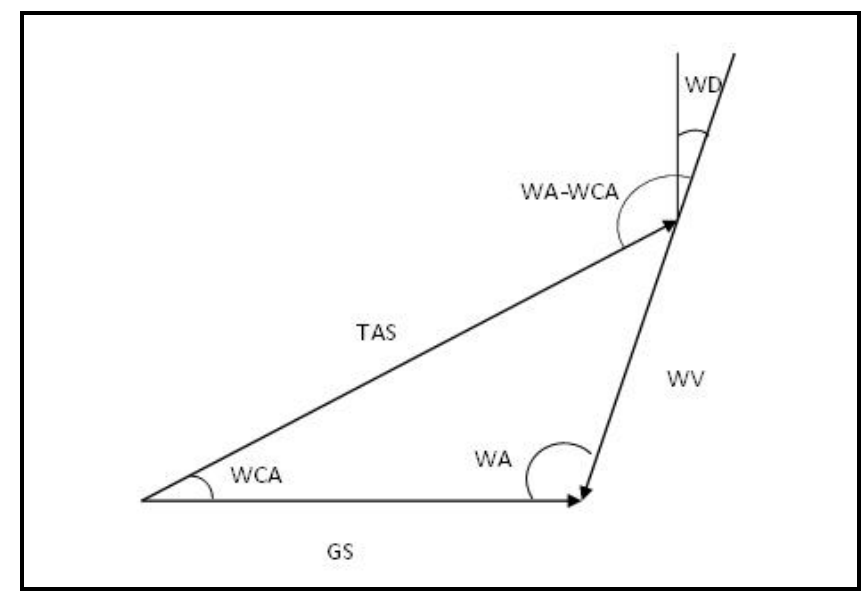

Figure 2.1 "Wind triangle" diagram

The algorithm that determines the value of the crabbing angle, and the resulting ground speed, called the "wind triangle" algorithm, is presented by Botez [8] and Botez [9]. The following computations are performed: 
If the relative wind angle, between the segment heading and the wind direction is $0^{\circ}$ or $180^{\circ}$, the crabbing angle is $0^{\circ}$, and the ground speed is:

$$
G S=T A S \mp W V
$$

where the "-" sign corresponds to head winds (wind angle $=0^{\circ}$ ), and "+" corresponds to tail winds ( wind angle $=180^{\circ}$ ).

If the relative wind angle is different than 0 or $180^{\circ}$, the ground speed and crabbing angle are computed using the next equations:

$$
W C A=\arcsin \left(\sin (W A) * \frac{W V}{T A S}\right)
$$

(Botez, [9], page 28)

$$
G S=T A S * \frac{\sin (W A-W C A)}{\sin (W A)}
$$

(Botez, [9], page 29)

It is noted that for a given speed schedule, and wind structure, the $T A S$ and the wind speed are changing with the altitude. That means that the crabbing angle and the ground speed are dependent of the flying altitude. Consequently, the segment flight time, computed as the quotient of the segment length and ground speed, is also dependent of the flying altitude. 


\subsection{Aircraft gross weight and center of gravity position}

The aircraft's gross weight $(\mathrm{gw})$ represents the total weight of the aircraft and is computed as the sum of the zero fuel gross weight (zfgw), and the fuel weight (fuel), as seen in Federal Aviation Administration [10]. The $z f g w$ includes the weight of the aircraft's structure and payload, that is applied at a specific location, along the longitudinal axis of the aircraft, and depends on the mass distribution of the structural elements of the aircraft and payload. The parameter that describes the position is the zero fuel center of gravity position (zfwcg), and can be expressed as the distance, in inches or millimeters, from the aircraft's center of gravity reference point, or in percentage of the Mean Aerodynamic Chord length $(M A C)$. The aircraft's center of gravity reference point is the point used as a reference in all center of gravity computations. It can be located at the datum, or at a given location along the longitudinal axis of the aircraft, defined by its distance (CGREFDIST) from the datum. The datum is the point on the longitudinal axis of the aircraft, from which all aircraft longitudinal quantities are defined.

As $z f g w$, and fuel weight are applied at different locations than the center of gravity reference point, each of them will produce a corresponding moment. The convention used in moment calculations, as described in Federal Aviation Administration [10], is that a positive moment is given by a weight force applied aft of the cg reference point, and negative if is applied forward of the cg reference point. The aircraft moment $(M a)$ is produced by the $z f g w$, and its magnitude, as a function of the $z f g w$ and $z f w c g$, is described through charts or data tables. The fuel weight generates the fuel moment $(M f)$. Its magnitude is a function only on the fuel weight, as the location of the fuel tanks, and the fuel mass distribution, function of the fuel weight, are aircraft design characteristics. The fuel moment is also described through charts or data tables. 


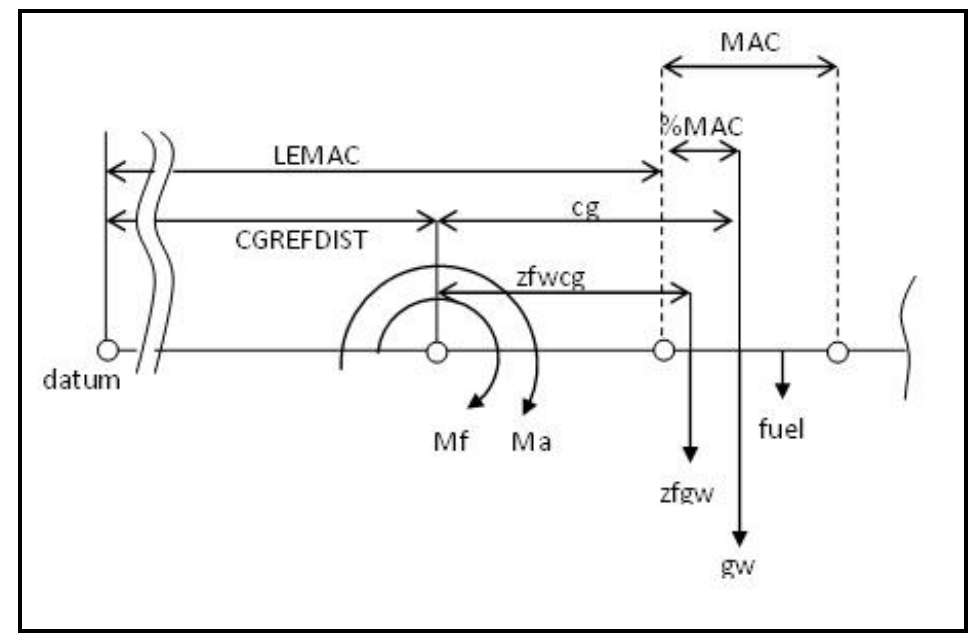

Figure 2.2 Aircraft weights and moments diagram

The total moment $(M t)$ is computed as the sum of $M a$ and $M f$. In accordance with the fundamental principles of mechanics, two systems of forces applied to an object are equivalent if their resulting forces and corresponding moments, computed with respect to the same reference point, are equal. Consequently, the point of application of the gross weight the aircraft center of gravity position $(\mathrm{cg})$ - is chosen so that the gross weight produces a total moment $(M t)$, equal to that produced by the assembly of $z f g w, z f w c g$ and fuel weights. Therefore, as described in Federal Aviation Administration [10], the position of the center of gravity is equal to the quotient of the total moment and the total weight. Consequently, the corresponding cg position, expressed in meters or feet, with respect to the cg reference point, is described by the following equation:

$$
c g(z f g w, z f w c g, f u e l)=\frac{M a(z f g w, z f w c g)+M f(f u e l)}{g w(z f g w, f u e l)}
$$

The cg position can also be expressed in percentage of the mean aerodynamic chord (MAC) length such as \%MAC. In this case, the position of the cg is referred to the wing leading edge mean aerodynamic chord position (LEMAC). Both $M A C$ and $L E M A C$ are known aircraft design parameters. Following the procedure described in Federal Aviation Administration [10], the equation used for determining the cg position, expressed in \%MAC, is: 


$$
\begin{aligned}
& c g(z f g w, z f w c g, f u e l)= \\
& \frac{\left(\frac{M a(z f g w, z f w c g)+M f(f u e l)}{g w(z f g w, f u e l)}+C G R E F D I S T-L E M A C\right) * 100}{M A C}
\end{aligned}
$$

\subsection{Maximal cruise altitude}

The maximal altitude achievable by an aircraft depends, as described by Liden [3], on the speed, the gross weight, and the altitude (through the effect of the climb fuel burn on the gross weight) of the aircraft at the time for which the determination of the altitude is made. It corresponds to the maximal altitude value for which the set of two parameters, the speed margin, and thrust margin, have values that are zero or positive.

As indicated by Liden [3], the speed margin is computed as the minimum of the difference between the aircraft's maximal and schedule speed, and the difference between the aircraft' schedule and minimal speed. Also, the thrust margin is computed, for a given altitude and speed schedule, as the difference between the maximum cruise thrust, and the thrust required to maintain a climb rate of $100 \mathrm{ft} / \mathrm{s}$. The actual parameters used in computing the maximal and minimal speed, as well as the altitude limitation imposed by the thrust margin are specific to each aircraft. They are determined by the particular aircraft model used for defining its corresponding performance tables. 



\section{CHAPTER 3}

\section{ALGORITHM DEVELOPMENT}

The development of a new algorithm, determining the optimal cruise altitude for a constant speed, level-flight, cruise segment is presented in this chapter. The optimization strategy chosen for the algorithm is presented first. Subsequently, the algorithm input and output variables, the structure of the algorithm and its implementation are described.

\subsection{The optimization strategy}

The critical factor that determined the strategy used in the optimization process is the requirement that the algorithm is deterministic, i.e. at different instances of time, same input data produces the same outputs. Therefore, statistical approaches such as meta-heuristic optimization methods were considered inappropriate from the beginning of the algorithm development due to their output dependency on factors such as the optimization starting point, candidate pool choice and size, or limitations imposed by the number of processing iterations. Consequently, a methodology that uses an analytical approach is chosen, based on the algorithm described by Liden [3].

\subsection{Input variables}

The algorithm input variables are divided into four categories: optimization configuration, aircraft design and performance description, flight segment configuration, and aircraft configuration. Each category is described in a sub-section of this section:

\subsubsection{Optimization configuration parameters}

These parameters define the particular conditions for which the optimization is performed. They are regarded as a set of constant-value algorithm configuration parameters set in accordance with the airline policy. They correspond to: 
- the cost index $(C I)$ - in $\mathrm{Kg} / \mathrm{min}$;

- optimization distance (OPT_DISTANCE), defining the length of the segment, in Nm;

- minimal cruise altitude (MIN_ALTITUDE), defining the lowest cruise altitude, in ft.

\subsubsection{Aircraft design and performance data}

The data described in this paragraph represents a subset of general data, specific to each aircraft, characterizing the aircraft's geometry, performances, capabilities, and limitations. The subset is limited to the data used by the optimization algorithm. They are divided into data specific for an aircraft whose cruise, constant speed, level-flight fuel burn model factors the cg position and data that is common to all aircraft.

The data specific for an aircraft whose cruise, constant speed, level-flight fuel burn model factors the cg position are:

- CGREFDIST - the cg reference point position, in meters, from the datum. Only used for aircraft models that factor the cg position;

- $L E M A C$ - the wing, leading edge mean aerodynamic chord position, in meters, from the datum. Only used for aircraft models that factor the cg position;

- $M A C$ - the wing, mean aerodynamic length, in meters. Used only for aircraft models that factor the cg position;

- aircraft moment $\left(M_{a}\right)$ - in $\mathrm{kg}^{*} \mathrm{~m}$, aircraft performance table describing the aircraft moment as a function of the $z f g w$ and $z f w c g$. Used only for aircraft models that factor the cg position;

- fuel moment $\left(M_{f}\right)$ - in $\mathrm{kg}^{*} \mathrm{~m}$, aircraft performance table describing the fuel moment as a function of the fuel weight. Used only for aircraft models that factor the cg position.

The data common to all aircraft are: 
- ALT_LIMIT - the maximal altitude, in $\mathrm{ft}$, at which the aircraft is allowed to fly, under any circumstances;

- fuel flow performance tables - one table for each speed mode $\left(f f_{I}\right.$ for IAS, and $f f_{M}$ for Mach mode) defining the fuel flow, in $\mathrm{Kg} / \mathrm{h}$, as a function of IAS/Mach, gw, ISA_Dev, and altitude;

- fuel correction factor - a dimensionless parameter, defined as performance tables or constant values, depending on the aircraft model. If the aircraft model defines it as performance tables, one table is defined for each speed mode $\left(f c r_{I}\right.$ for IAS, and $f c r_{M}$ for Mach mode), as a function of $c g$, IAS/Mach, gw, and altitude;

- $v m o$ - a constant, or a performance table as a function of altitude, defining the maximal IAS speed, in Kts;

- $m m o$ - a constant, or a performance table as a function of altitude, defining the maximum Mach number;

- minspeed - a performance table defining the minimal speed (Mach number), as a function of the product between the aircraft gross weight $(g w)$ and the density ratio $(\delta)$, at the considered altitude;

- trust margin max_altitude limit - a performance table defining the maximal altitude limitation due to the thrust margin, in $\mathrm{ft}$. It is described as a function that depends on a combination of parameters specific to each aircraft that may include the gross weight, Mach number, cg, and ISA_Dev.

\subsubsection{Flight segment configuration}

The four parameters corresponding to this category define the characteristics associated with the cruise flight segment for which the optimization is performed, as follows:

- segment heading (heading), in deg;

- wind structure (wind), defining the wind layers at up to four altitudes. Each layer is characterized by an altitude - in ft, wind direction (direction) - in degrees, and wind speed (speed) - in Kts; 
- speed schedule (schedule), defining the pair of Mach number and IAS. The IAS value is defined in Kts;

- $I S A \_D e v$, defining the atmosphere standard temperature deviation, in ${ }^{\circ} \mathrm{K}$.

\subsubsection{Aircraft configuration}

The aircraft parameters used by the algorithm and described in this section are:

- $z f g w$ - the aircraft zero fuel gross weight, in $\mathrm{Kg}$. Its value is set before take-off and remains unchanged for the duration of the flight;

- $z f w c g$ - the zero fuel weight center of gravity position, in \%MAC. Used only for the aircrafts whose fuel burn model considers the cg position. Its value is set before take-off and remains unchanged for the duration of the flight;

- fuel - the fuel weight, in $\mathrm{Kg}$. Its value decreases constantly as the fuel is burned at a fuel burn rate $(f b r)$ that depends on the aircraft configuration and flight conditions;

- current altitude - the aircraft altitude, in $\mathrm{ft}$, at the time when the optimal altitude is requested.

\subsection{Output data}

The objective of the optimization algorithm is to determine the optimal altitude for flying a selected constant-speed, level-flight, cruise segment. Consequently, the output data is represented by the optimal cruise altitude (optimal_alt), in ft. However, due to the fact that the optimal cruise altitude functionality was not available on the platform used for producing the validation data, the algorithm proposed in this thesis also provides the values for the segment flight times, fuel burns, and total costs - corresponding to the set of valid cruise altitudes. This facilitates the evaluation of the performances of the new fuel burn computing algorithm. 


\subsection{Algorithm processing steps}

The algorithm follows the general processing steps as presented by Liden [3]. They are:

- determining the set of cruise altitudes used in the process of optimization;

- computing the flight time at each altitude in the set of cruise altitudes;

- computing the fuel burn at each altitude in the set of cruise altitudes;

- computing the total cost at each altitude in the set of cruise altitudes;

- determining the altitude yielding the minimal cost.

These steps rely on auxiliary functions that perform general tasks such as: $I A S$, and Mach to $T A S$ conversion, ground speed, and cg computing, interpolation, and numerical integration.

\subsection{Algorithm implementation}

Having chosen the type of algorithm employed (analytical) and knowing the number and order of the computing steps used for determining the optimal altitude, the implementation addresses two principal objectives: first, an algorithm computing the fuel burn, that accounts for the continuous variation of the fuel burn rate with the gross weight (and cg); second, the computations will be performed in a manner that is compatible with the algorithm's response time requirements.

Analyzing the set of algorithm input parameters, it can be observed that they can be regrouped in three categories:

1) Parameters that have a constant value for the duration of the flight - zfgw, zfwcg, CI, OPT_DISTANCE, MIN_ALTITUDE, as well as the aircraft performance and design data.

2) Variables whose values may change, but at longer intervals of time such as the speed schedule (IAS, Mach), ISA_Dev, segment heading, and wind structure - and they are considered constant on the segment for which the optimal altitude is computed. 
3) Variables whose values are changing constantly under the influence or as a consequence of the fuel burn - i.e. the fuel, and thus the $g w$ and $c g$.

It can be noted that certain computations can only be performed at the time at which the determination of the optimal altitude is requested, as they are dependent on aircraft's gross weight and $c g$. These computations refer to: maximal altitude, the fuel burn and the total cost, for each altitude in the determined range of acceptable cruise altitudes. However, certain computations that depend only on parameters that belong to categories 1) and 2), above, can be performed upon a parameter value's modification, and the results used in all subsequent computations. One such example is the generation of IAS to TAS and Mach to TAS conversion tables. The modules implementing different parameter calculations are described in the next sub-sections.

\subsubsection{TAS and crossover altitude module}

This module is executed at each modification of the speed schedule. It pre-computes the $I A S$ to TAS and Mach to TAS conversion tables, and the crossover altitude, for the set of altitudes, multiple of $1000 \mathrm{ft}$., situated between the MIN_ALTITUDE and ALT_LIMIT. The module ensures that valid $T A S$ values are available for any given speed schedule and cruise altitude range.

The $I A S$ to $T A S$ conversion is performed using equations (2.15) and (2.16), and the Mach to $T A S$ conversion is performed using equation (2.17). The corresponding parameters of the standard atmosphere, used in this thesis, are those presented in Appendix B of Asselin, [7].

The crossover altitude is detected, by comparing the two sets of TAS values, as the altitude at which the $T A S(M a c h)$ equals the $T A S(I A S)$. 


\subsubsection{The maximal cruise altitude and cruise altitude range module}

This module computes the range of valid cruise altitudes, corresponding to the aircraft's status at the initial point of the cruise segment for which the optimal altitude is determined. It is executed upon each optimal altitude request.

For each altitude, multiple of 1000ft., situated between MIN_ALTITUDE and ALT_LIMIT, it computes the following parameters:

- The TAS_min(altitude), the TAS corresponding to the Mach number computed from the minspeed interpolation table, function of the $g w$, and the pressure ratio at the evaluated altitude, $\delta$ (altitude).

- The vmo_tAS(altitude), and mmo_TAS(altitude) corresponding to the vmo and mmo aircraft performance parameters/ interpolation tables.

It then compares these values with the aircraft TAS(altitude), computed from the speed schedule (IAS or Mach, function of the position of the crossover altitude value). The speed_limited_altitude is the highest altitude at which TAS(altitude) is larger than TAS_min(altitude), and smaller than vmo_TAS(altitude) and mmo_TAS(altitude). Then, it computes the max_thrust_altitude, from the trust margin max_altitude limit performance table, as a function of a combination of gross weight, Mach number, cg, and ISA_Dev parameters, depending on the aircraft model.

The maximal cruise altitude is computed as the minimum between the speed_limited_altitude and the max_thrust_altitude. Consequently, the range of valid cruise altitudes is composed of the altitudes, multiples of 1,000 ft., situated between the MIN_ALTITUDE and maximal cruise altitude. 


\subsubsection{Ground speeds and segment flight times}

This module is executed upon each request for the optimal altitude. First, it computes the ground speed for each altitude, multiple of 1,000 ft. in the range of valid cruise altitudes. For still air conditions, the ground speed at any altitude, is equal to TAS at that same altitude. For constant wind conditions, the ground speed, at any altitude, is computed in two steps. First, the wind parameters (direction and speed) are determined from the wind table associated with the cruise segment, through linear interpolation. Subsequently, the ground speed is computed using the "driftcorr" MATLAB function, implementing the "wind triangle" algorithm. The arguments passed to the "driftcorr" function are: the TAS, cruise segment heading, wind direction and wind speed. Finally, the cruise segment flight time, at each altitude is computed by dividing the cruise segment's length (OPT_DISTANCE), to the ground speed at the corresponding altitude.

\subsubsection{The fuel burn}

The actual fuel burn value can only be computed at the moment of the request for the optimal altitude, due to its dependency on the $g w$ (and $c g$ ). More, computing the fuel burn, considering the continuous variation of the $g w$ (and $c g$ ) along the cruise segment, requires two elements: Firstly, expressing the $f b r$ as a function of time. Secondly, performing the integration of the, time dependent, $f b r$ function, on a time domain corresponding to the segment flight time. The integration is a time, and computing resources demanding process. It becomes apparent that meeting the response time requirements cannot be achieved by performing all fuel burn computations at the moment of the optimal altitude request. Therefore, the method presented in this thesis performs the computations in steps, at different times. It takes into account two facts: first, aircraft performances are defined through linear interpolation tables; second, the rate of variation of each of the variables, that determine the fuel burn rate, corresponds to one of the three categories presented in the beginning of the section 3.5. It means that there is a set of values for each variable associated with the input of the interpolation tables that defines linearity domains for the output, interpolated, variable. 
This propriety is used in finding the time-dependent expression of the fuel burn function, $f b r(t)$. It also means that we can decompose the fuel burn computations in three sub-modules (steps), corresponding to the three categories of variables.

The implementation of the algorithm is function of the fuel burn aircraft model used $-c g$ dependent or $c g$ independent. As presented in sub-section 3.2.2, two sets of fuel flow and fuel correction factor performance tables are defined, one for each type of cruise speeds - IAS or Mach. Since the difference between the two sets of tables refers only to the type of the speed, the computations associated with each set are identical. Consequently, the implementation of the fuel burn computation algorithm is described only for the Mach index speeds as for the IAS the algorithm is identical.

The algorithm is composed of three modules as follows:

- An initialization module, executed before take-off, once the aircraft $z f g w,(z f w c g)$ and fuel values are set. A series of auxiliary tables are built and subsequently used by the next two modules.

- The intermediary module, that builds $I A S$ and Mach-based fuel burn look-up tables that describe the dependency between the initial gw, IAS/Mach, ISA_Dev, the cruise altitude, the flight time, and the final gw, thus the fuel burn. The module is executed each time the speed schedule or ISA_Dev parameters change, or as required by the update strategy. The tables are generated for altitudes situated between MIN_ALTITUDE and ALT_LIMIT.

- The fuel burn module, extracting the fuel burn quantity as a function of the $g w$ at the initial point of the cruise segment, the evaluated cruise altitude, and the corresponding flight time. It is executed, at each request for the optimal altitude, a number of times equal to the pre-determined number of valid cruise altitudes.

\subsubsection{The initialization module}

The main goal of this module is to determine the set of gross weight values, $\left\{g w_{i}\right\}$, for which every interval $\left[g w_{i}, g w_{i+1}\right]$ maps linearity domains in all performance interpolation tables 
used in the fuel burn rate computation. For the $c g$ independent model, the module only identifies and assembles the $g w$ values defined in the $f f_{I}$, and $f f_{M}$ performance tables.

For the $c g$ dependent model however, the $g w$ values explicitly, or implicitly, defined by the $f c r_{I}, f c r_{M}$, and $M_{f}$ performance tables are also considered. First, it determines the set of $\left\{g w_{j}\right\}$ values, explicitly defined in the $f c r_{I}$ and $f c r_{M}$ tables. Then, a new fuel moment table as a function of $g w, M_{f g w}(g w)$ is generated. The input variable, fuel, is replaced by the corresponding gross weight:

$$
g w_{k}=z f g w+f u e l_{k}
$$

Subsequently, the set of $g w$ values, $\left\{g w_{p}\right\}$ is determined, that corresponds to the $c g$ values defined in the $f_{c r}$ tables. As $M_{f g w}(g w)$ is defined as a linear interpolation table, on each domain $\left[g w_{k}, g w_{k+1}\right]$ the rate of variation of the fuel moment is constant. Its value is computed using the next equation:

$$
\left.\frac{\partial M_{f g w}}{\partial g w}\right|_{g w_{k}}=\frac{M_{f g w}\left(g w_{k+1}\right)-M_{f g w}\left(g w_{k}\right)}{g w_{k+1}-g w_{k}}
$$

Consequently, the value of the fuel moment corresponding to a gross weight in the domain $\left[g w_{k}, g w_{k+1}\right]$ is computed using the equation:

$$
M_{f g w}(g w)=M_{f g w}\left(g w_{k+1}\right)-\left.\frac{\partial M_{f g w}}{\partial g w}\right|_{g w_{k}} * g w_{k+1}+\left.\frac{\partial M_{f g w}}{\partial g w}\right|_{g w_{k}} * g w
$$

By expressing, in equation (2.22), the fuel moment function of the $g w$, using the $M_{f g w}(g w)$, the equation describing the $c g$ function of the $g w$ becomes: 


$$
c g(g w)=\frac{\left(\frac{M_{a}(z f g w, z f w c g)+M_{f g w}(g w)}{g w}+C G R E F D I S T-L E M A C\right) * 100}{M A C}
$$

Consequently, on a gross weight domain, the gross weight value corresponding to a given $c g$ position can be computed by replacing $M_{f g w}(g w)$ given by equation (3.3) into equation (3.4):

$$
g w(c g)=\frac{\left(M_{a}(z f g w, z f w c g)+M_{f g w}\left(g w_{k+1}\right)-\left.\frac{\partial M_{f g w}}{\partial g w}\right|_{g w_{k}} * g w_{k+1}\right)}{\left(\frac{c g * M A C}{100}-C G R E F D I S T+L E M A C-\left.\frac{\partial M_{f g w}}{\partial g w}\right|_{g w_{k}}\right)}
$$

Therefore, the set of gross weight values, $\left\{g w_{p}\right\}$, is computed using equation (3.5), by evaluating each $c g$ value defined by the $f c r$ tables, on all $\left[g w_{k}, g w_{k+1}\right]$ gross weight domains. A $g w_{p}$ thus computed is considered valid, and retained, if its value lies within the gross weight domain on which it was computed. Finally, the $\left\{g w_{k}\right\},\left\{g w_{j}\right\}$ and $\left\{g w_{p}\right\}$ sets are added to the initial set of $\left\{g w_{i}\right\}$ values:

$$
\left\{g w_{i}\right\}=\left\{g w_{i}\right\} \cup\left\{g w_{j}\right\} \cup\left\{g w_{k}\right\} \cup\left\{g w_{p}\right\}
$$

This new set of gross weight values $\left\{g w_{i}\right\}$ ensures that each domain $\left[g w_{i}, g w_{i+1}\right]$ corresponds to $g w$ and $c g$ linearity domains, in all performance interpolation tables used for computing the fuel burn rate. Next, the $M_{f g w}$ table is rebuilt according to the new set of $\left\{g w_{i}\right\}$ values. Two more auxiliary tables, used by the intermediary module, are built for the same set of $\left\{g w_{i}\right\}$ values. First, the $C G_{-} A T_{-} G W\left(g w_{i}\right)$ table, storing the $c g$ position, corresponding to each $g w$ in the $\left\{g w_{i}\right\}$ set, is computed using equation (3.4). The second table, called CG_SLOPE $\left(g w_{i}\right)$, stores, for each domain $\left[g w_{i}, g w_{i+1}\right]$, a coefficient that is used to determine the $c g$ variation $(d c g)$ function of the gross weight variation $(d g w)$, where both are referenced to their corresponding value at $g w_{i+l}$. To determine the equation used to compute the elements of the table we are using the next equation: 


$$
d c g(g w)=c g\left(g w_{i+1}\right)-c g(g w)
$$

In equation (3.7), replacing the cg values with the values given by equation (3.4), and subsequently $M_{f g w}(g w)$ with equation (3.3), we obtain:

$$
\begin{aligned}
d c g(g w) & =\left(\frac{100 *\left(M_{a}(z f g w, z f w c g)+M_{f g w}\left(g w_{i+1}\right)-\left.\frac{\partial M_{f g w}}{\partial g w}\right|_{g w_{i}} g w_{i+1}\right)}{M A C}\right) * \\
& \left(\frac{1}{g w_{i+1}}-\frac{1}{g w_{i}}\right)
\end{aligned}
$$

Denoting:

$$
d g w=g w_{i+1}-g w
$$

and

$$
C G_{-} \operatorname{SLOPE}\left(g w_{i}\right)=\left(\frac{100 *\left(M_{a}(z f g w, z f w c g)+M_{f g w}\left(g w_{i+1}\right)-\left.\frac{\partial M_{f g w}}{\partial g w}\right|_{g w_{i}} g w_{i+1}\right)}{M A C^{*} g w_{i+1}}\right)
$$

the equation (3.8) can be written as a function of $d g w$, therefore it becomes:

$$
d c g(d g w)=C G \_S L O P E\left(g w_{i}\right) *\left(\frac{d g w}{g w_{i+1}-d g w}\right)
$$




\subsubsection{The intermediary module}

This module constructs, for a given speed schedule, and ISA_Dev, a structure describing the relationship between the aircraft's initial $g w$, the cruise altitude, the flight time, and the final $g w$. The data is assembled for a number of altitudes, multiples of 1,000 ft, situated between the MIN_ALTITUDE and ALT_LIMIT. The IAS or Mach performances are characterized, depending on the corresponding altitude position relative to the crossover altitude. At each altitude, the fuel burn data is generated for a number of gross weight domains that depend on the structure's update strategy, and the OPT_DISTANCE. It should cover, at least, the fuel burn that can occur on flying the cruise segment, under any conditions. The implementation considers the generation of the fuel burn data for the entire set of gross weight domains, starting with the one containing the $g w$ value at the time the data is generated, further to the $g w$ corresponding to fuel $=0$. It allows the investigation of the module's response time performance, as a function of the gross weight range.

The present paragraph describes the computations performed for Mach index speeds, at a given altitude on a gross weight domain $\left[g w_{i}, g w_{i+1}\right]$, for $c g$ dependent and $c g$ independent aircraft models. At $I A S$ speeds, the computations are identical, but are using the $I A S$ performance interpolation tables $\left(f f_{1}\right.$, and $f\left(r_{I}\right)$. First, the fuel burn rate $(f b r)$ equation, function of the $d g w$, is developed using the equation of the linear interpolation. Then the equation is rewritten, to describe the $f b r$ variation function of time. Finally, the timedependent $f b r$ function is integrated using the Runge-Kutta 4 (RK4) algorithm, as described by Butcher [11].

The fuel burn rate (fbr) is computed as the product between the fuel flow (ff) and the fuel correction factor $(\mathrm{fcr})$. The steps needed for its calculation are shown next. Denoting:

$$
f f_{1}=f f_{M}\left(\text { Mach, } g w_{i+1}, I S A_{-} \text {Dev, altitude }\right)
$$

and 


$$
f f_{2}=f f_{M}\left(\text { Mach, } g w_{i}, I S A_{-} \text {Dev, altitude }\right)
$$

the value of the fuel flow, at a gross weight described by the $d g w$, is computed by linear interpolation, using the equation:

$$
f f(d g w)=f f_{1}-\frac{f f_{1}-f f_{2}}{g w_{i+1}-g w_{i}} d g w
$$

Denoting:

$$
A_{0}=f f_{1}
$$

and

$$
A_{1}=\frac{f f_{1}-f f_{2}}{g w_{i+1}-g w_{i}}
$$

the equation (3.14) becomes:

$$
f f(d g w)=A_{0}-A_{1}^{*} d g w
$$

For the $c g$ independent aircraft model and Mach index speeds, the fuel correction factor $f c r_{M}$ is a constant value. Therefore, denoting $\mathrm{C}_{0}=f c r_{M}$, the equation of the fuel burn rate as a function of the $d g w$ is:

$$
f b r(d g w)=C_{0}\left(A_{0}-A_{1}^{*} d g w\right)
$$

Observing that the $d g w$ changes with time, as the fuel is burned, the $f b r$ variation is described as a function of time: 


$$
f b r(t)=C_{0}\left(A_{0}-A_{1}^{*} d g w(t)\right)
$$

There is also a direct relationship between $d g w(t)$ and $f b r(t)$, as the gross weight variation is produced as a result of burning the fuel at a rate described by the $f b r(t)$. Consequently, the equation that connects $d g w$ and $f b r$ is:

$$
d g w(t)=\int f b r(t) d t
$$

Denoting $d g w(t)=I$ implies that $f b r(t)=d I / d t$. Therefore, equation (3.19) becomes:

$$
\frac{d I}{d t}=C_{0}\left(A_{0}-A_{1}^{*} I\right)
$$

This differential equation describes the gross weight variation ( $d g w)$ as a function of the flight time, on a gross weight domain $\left[g w_{i}, g w_{i+1}\right]$, for the $c g$ independent aircraft model.

For the cg dependent aircraft model, for Mach index speeds, the fuel correction factor $(f c r)$ is obtained from the $\mathrm{fcr}_{M}$ interpolation table. We denote:

$$
\begin{aligned}
& c r_{11}=f c r_{M}\left(C G_{-} A T_{-} G W\left(g w_{i+1}\right), M a c h, g w_{i+1}, \text { altitude }\right) \\
& c r_{12}=f c r_{M}\left(C G_{-} A T_{-} G W\left(g w_{i}\right), M a c h, g w_{i+1}, \text { altitude }\right) \\
& c r_{21}=f c r_{M}\left(C G_{-} A T_{-} G W\left(g w_{i+1}\right), M a c h, g w_{i}, \text { altitude }\right) \\
& c r_{22}=f c r_{M}\left(C G_{-} A T_{-} G W\left(g w_{i}\right), M a c h, g w_{i}, \text { altitude }\right)
\end{aligned}
$$

Interpolating, along the $g w$ input parameter of the fuel correction factor performance table, leads to the equations: 


$$
\begin{aligned}
& f c r_{1}=c r_{11}-\frac{c r_{11}-c r_{21}}{g w_{i+1}-g w_{i}} d g w \\
& f c r_{2}=c r_{12}-\frac{c r_{12}-c r_{22}}{g w_{i+1}-g w_{i}} d g w
\end{aligned}
$$

Subsequently, interpolating between the values of $f \mathrm{cr}_{1}$ and $f_{\mathrm{Cr}}$, to account for the variation of the $c g$, with respect to $c g_{i+1}=c g\left(g w_{i+1}\right)$, leads to:

$$
f c r=f c r_{1}-\frac{f c r_{1}-f c r_{2}}{c g\left(g w_{i+1}\right)-c g\left(g w_{i}\right)} d c g
$$

Replacing the terms of equation (3.24), with their definitions given in equations (3.11),(3.22) and (3.23), and denoting:

$$
\begin{aligned}
& B_{0}=c r_{11} g w_{i+1} \\
& B_{1}=c r_{11}+\frac{c r_{11}-c r_{21}}{g w_{i+1}-g w_{i}} g w_{i+1}+\frac{\left(c r_{11}-c r_{12}\right) C G_{-} S L O P E\left(g w_{i}\right)}{C G_{-} A T_{-} G W\left(g w_{i+1}\right)-C G_{-} A T_{-} G W\left(g w_{i}\right)} \\
& B_{2}=\frac{1}{g w_{i+1}-g w_{i}}\left(c r_{11}-c r_{21}+\frac{\left(c r_{11}-c r_{12}-c r_{21}+c r_{22}\right) C G_{-} S L O P E\left(g w_{i}\right)}{C G_{-} A T_{-} G W\left(g w_{i+1}\right)-C G_{-} A T_{-} G W\left(g w_{i}\right)}\right) \\
& C_{0}=g w_{i+1}
\end{aligned}
$$

the equation describing $f(r(d g w)$ becomes:

$$
f c r(d g w)=\frac{B_{0}-B_{1} * d g w+B_{2} * d g w^{2}}{C_{0}-d g w}
$$

Consequently, the equation describing the $f b r(d g w)$, for the $c g$ dependent aircraft model, is:

$$
f b r(d g w)=\frac{\left(A_{0}-A_{1} * d g w\right)\left(B_{0}-B_{1} * d g w+B_{2} * d g w^{2}\right)}{C_{0}-d g w}
$$


Considering equation (3.20) and denoting $d g w(t)=I$ implies that $f b r(t)=d I / d t$. Replacing the $d g w(t)$ and $f b r(t)$ in equation (3.27) leads to the time dependent differential equation:

$$
\frac{d I}{d t}=\frac{\left(A_{0}-A_{1} * I\right)\left(B_{0}-B_{1}^{*} I+B_{2} * I^{2}\right)}{C_{0}-I}
$$

For each gross weight domain, and altitude, a look-up table describing the gross weight variation with time is produced by integration of equation (3.21), or (3.28), depending on the aircraft modeling, using the RK4 numerical integration algorithm. The gross weight information stored in the look-up table corresponds to time instances, multiples of the integration time step value, referenced to the beginning of the gross weight domain. Therefore, searches in the look-up table can be performed depending on the gross weight, or the flight time.

The Runge-Kutta numerical integration is performed using the "ode45" MATLAB function. The integration time step was chosen as the minimum between $30 \mathrm{sec}$ and the time required to burn the entire quantity of fuel corresponding to the gross weight domain. In order to facilitate the fuel burn computations by the fuel burn module, the time required to burn the entire quantity of fuel corresponding to the gross weight domain is also stored in the fuelburn look-up table.

\subsubsection{The fuel burn module}

The fuel burn module computes fuel burn values, at a given altitude, as the difference between the value of the gross weight, at the beginning of the considered cruise segment, and the value of the gross weight after flying for a period equal to the cruise segment's flight time. The gross weight domain containing the aircraft's gross weight value, at the beginning of the cruise segment, is identified. Subsequently, the corresponding time offset, from the domain's initial gross weight is determined. By subtracting it from the gross weight domain's total time, the flight time required to reach the domain's final gross weight is determined. 
Then, a series of iterations are performed on successive gross weight domains, starting with the initial domain. Upon each iteration, the flight time corresponding to the selected domain and the cruise flight time are compared. If the domain's flight time is smaller, its value is subtracted from the cruise flight time, and the processing advances to the next iteration, corresponding to the next gross weight domain. If the domain's flight time is larger, the final gross weight is computed as the value corresponding to the time offset, from the beginning of the domain, equal to the value of the cruise flight time. The fuel burn is then computed as the difference between the initial and the final gross weight.

\subsubsection{The total cost}

The total cost $\left(C_{T O T}\right)$, expressed in kilograms of fuel, is computed for each altitude in the set of valid cruise altitudes, using equation (2.6). The value of the integral term is retrieved from the look-up table using the code implementing the fuel burn module.

\subsubsection{The optimal altitude module}

The optimal altitude module provides the functionality that represents the main object of the present thesis. It is executed upon each optimal altitude request and implements the processing steps described in the sub-section 3.4. It relies on the functions and data provided by the modules described in sub-section 3.5.1 to 3.5.5, to compute the total cost and fuel burn for each altitude in the range of valid cruise altitudes.

Subsequently, the optimal altitude is selected as the altitude yielding the minimal cost. If two or more altitudes present the same minimal cost, the altitude also yielding the minimal fuel burn is selected as the optimal altitude. If two or more altitudes yield the minimal cost and minimal fuel burn, the selected altitude corresponds to that closest to the aircraft's altitude at the time the optimal altitude is computed. 


\title{
CHAPTER 4
}

\begin{abstract}
ALGORITHM VALIDATION
The algorithm was implemented for three aircraft models: Airbus A310, Lockheed L1011, and Sukhoi RRJ. The validation strategy adopted for each of the three models depended upon the particularities of the corresponding test platform provided by our research partner CMC Electronics - Esterline. It is important to note that the validation was not intended, in any way, to characterize the PTT's or aircraft's cruise performances. Such an endeavor requires a significant amount of time and resources and was already performed as a part of each product's certification processes.
\end{abstract}

The algorithm's code was developed in MATLAB, and executed on a Microsoft XP - based, PC platform. For the Airbus A310 and Sukhoi RRJ aircrafts, the main validation data was produced on a test platform, composed of a PC-based FMS simulator, the CMA9000 PTT, replicating the CMC Electronics -Esterline CMA9000 FMS. As the optimal altitude function, implemented by the algorithm described in this thesis, was not available on the test platform, the optimal altitude validation data was computed using the main validation data (segment flight times and fuel burns), generated by the CMA9000 PTT. The Lockheed L1011 validation platform also included a Flightsim 9.1-based aircraft simulator capable of flying the flight plan programmed on the PTT. The aircraft simulator allowed the recording of the variation with time of different aircraft parameters, including the aircraft's gross weight.

All tests were performed for cruise segments of 500 Nautical miles (399.59Nm for L1011), corresponding to approximately 1 hour of flight. For the A310 and RRJ models the validation followed three objectives. The first objective of the validation was the comparison of the optimal altitude computed by the algorithm with the optimal altitude computed using the flight times and fuel burns produced by the PTT. The second objective was the evaluation of the performances of the fuel burn computing algorithm. The third objective was the 
investigation of the execution times of each of the three modules implementing the algorithm. For the L1011 model the objective of the validation was the evaluation of the fuel burn algorithm performances by comparison with the values computed by the PTT and the Flightsim 9.1 at the optimal altitude computed by the algorithm. This was a limitation determined by the time required to obtain the Flightsim validation data at one altitude (the cruise segment's flight time).

The number of test cases that were evaluated was limited by the time and human resources available for generating the validation data. Each test was generated manually, i.e. platform configuration and data retrieval for each altitude, and each test case, required user intervention. Even without such limitations, an extensive investigation of the algorithm performances would have been impractical, due to the large number of possible combinations of the input parameters (IAS and Mach index speeds, wind structure, standard temperature deviation, zero fuel gross weight, zero fuel weight center of gravity position, fuel weight, minimal cruise altitude, the optimization distance, cruise segment's heading and cost index). While each of the above mentioned input parameters has an influence on the final value of the optimal altitude, the nature of their influence is not the same. For instance, cruise segment heading and wind structure are only relevant for constant wind conditions, through the relative wind angle's influence on ground speed and segment flight time. Also, the standard temperature deviation influences the optimal altitude through the fuel burn rate, hence the fuel burn. However, the evaluation of the algorithm performances for still air conditions and one value of the ISA_Dev provided valid data related to the fuel burn and optimal altitude modeling. For these reasons, all test cases considered a cruise segment heading of 0 deg (North), still air and a standard temperature deviation, ISA_Dev, equal to $0^{\circ} \mathrm{K}$. The value of the optimal altitude was influenced by the minimal cruise altitude by means of the number of evaluated cruise altitudes. In order to determine the values describing algorithm modules' maximal (worst) execution times, all test cases considered a minimal cruise altitude value of 20,000ft. For example, for the A310 these values were obtained by generating fuel burn look-up tables for 21 altitudes, and performing cost evaluations of up to 21 altitudes. 
According to CMC Electronics, the pair of $I A S$ and Mach values defining a cruise segment' speed schedule are linked by the following rule: the $I A S$ value of $280 \mathrm{Kts}$ is paired with a Mach value of 0.78 ; subsequently, an IAS variation of $20 \mathrm{Kts}$ corresponds to a Mach variation of 0.02 .

For the A310 and RRJ models, the algorithm performances were evaluated for a set of cost index values equal to $0,15,35,50$, and 100 . Upon analysis of the algorithm and its validation data it was found that a difference existed between the flight times computed by the algorithm and PTT, respectively, that may be explained by two main factors. The first factor refers to differences in code implementation and data processing due to platform differences. The second factor relates to the way in which the cruise segment is processed. The PTT decomposes the cruise segment in a number of sub-segments, of up to a predetermined length, required by their respective fuel burn computing algorithm. It then computes the total flight time, and the total fuel burn, as the sum of the sub-segments' flight times, and fuel burns respectively. For the tests performed on the PTT, the cruise sub-segments' length was set at $50 \mathrm{Nm}$ for A310 and $99.99 \mathrm{Nm}$ for RRJ. On the contrary, the algorithm presented in this thesis computes the segment flight times and the fuel burns for the entire segment independently of its length.

As the segment flight time is a parameter that influences both the fuel cost, and the non fuel cost, a second version of the algorithm was developed, that computed the optimal altitude, fuel burn and total cost, using the cruise altitude range and corresponding segment flight times computed by the PTT platform. Thus a better analysis of the optimal altitude, and fuel burn is obtained, where the differences are specific to the fuel burn computing algorithm only. The second algorithm was evaluated for the same set of test configurations, and cost index values. The results of the first algorithm, identified as "Algorithm 1", and the results of the second algorithm, identified as "Algorithm 2", are presented side by side. 
The execution times of each of the three main modules: initialization, intermediary and optimal altitude module were measured using the "tic" and "toc" MATLAB functions.

The results corresponding to each of the two developed algorithms describe the algorithm performances from two perspectives, as follows:

1) Algorithm performances, characterized by:

a) The difference between the optimal altitude computed by the algorithm and the corresponding optimal altitude computed using the PTT validation data.

b) The relative difference between the flight time, fuel burn and total cost values computed by the algorithm at the optimal altitude computed by the algorithm, and at the optimal altitude computed using the PTT validation data, respectively.

c) The relative difference between the flight time, fuel burn and total cost values computed by the algorithm and the values computed using the PTT validation data, respectively, at the optimal altitude computed by the algorithm.

2) Algorithm execution time, for each of the three algorithm modules: initialization, intermediary and optimal altitude.

For the L1011 model, the aircraft's $z f g w$ and fuel weight, thus $g w$, at the initial point of the cruise segment along with the corresponding cruise segment's flight time, computed by the PTT, were used for determining the fuel burn values computed by the Flightsim and the algorithm. Using the PTT-computed flight time was important for two reasons: firstly, the Flightsim cannot provide the data correlating the flight time and aircraft position relative to the PTT flight plan. Consequently, as the aircraft's gw (therefore the fuel weight) data recorded by the Flightsim is function of the flight time, it is impossible to extract the information related to the fuel burn function of the aircraft's position along the cruise segment; secondly, this allows to compare the PTT, Flightsim and algorithm fuel burn values for identical flight conditions, therefore, emphasizing the differences that are caused by the fuel burn computing model only. For the L1011 tests, the PTT cruise sub-segments' length was set at $99.99 \mathrm{Nm}$. 


\subsection{The test results for Airbus A310}

A number of 181 still air test configurations, corresponding to a cruise segment of $500 \mathrm{Nm}$, were considered as described by the Table 4-1 below. They were chosen to cover the aircraft's range of $I A S$ and Mach index speeds, $z f g w, z f w c g$ and fuel values.

Table 4-1 Description of the A310 test configurations

\begin{tabular}{|c|c|c|c|}
\hline $\begin{array}{c}\text { IAS/Mach } \\
\mathrm{Kts} /-\end{array}$ & $\begin{array}{c}\text { zfgw } \\
* 1,000 \mathrm{Kg}\end{array}$ & $\begin{array}{c}\text { zfwcg } \\
\text { \%MAC }\end{array}$ & $\begin{array}{c}\text { fuel } \\
* 1,000 \mathrm{Kg}\end{array}$ \\
\hline $240 / 0.74$ & 80 & $16,22,28,34,40$ & $15,25,35$ \\
\hline $240 / 0.74$ & 90 & 16 & 15,25 \\
\hline $240 / 0.74$ & 90 & 28 & $15,25,35$ \\
\hline $280 / 0.78$ & 80 & $16,28,34,40$ & $15,25,35,45,55$ \\
\hline $280 / 0.78$ & 80 & 22 & $25,35,45,55$ \\
\hline $280 / 0.78$ & 90 & $16,22,28,34,40$ & $15,25,35,45,55$ \\
\hline $280 / 0.78$ & 100 & 16 & $15,25,35$ \\
\hline $280 / 0.78$ & 100 & 22 & $15,25,35,55$ \\
\hline $280 / 0.78$ & 100 & 28 & $25,35,45,55$ \\
\hline $280 / 0.78$ & 100 & 34,40 & $15,25,35,45,55$ \\
\hline $320 / 0.82$ & 80 & $16,22,28,34$ & $15,25,35,45,55$ \\
\hline $320 / 0.82$ & 80 & 40 & $15,25,35,45$ \\
\hline $320 / 0.82$ & 90 & $16,28,34$ & $15,25,35,45,55$ \\
\hline $320 / 0.82$ & 90 & 22 & $15,25,35,45$ \\
\hline $320 / 0.82$ & 90 & 40 & $15,35,45,55$ \\
\hline $320 / 0.82$ & 100 & $16,22,28,34,40$ & $15,25,35,45$ \\
\hline $340 / 0.84$ & 90 & 16 & $15,25,35,45$ \\
\hline $340 / 0.84$ & 90 & $22,28,34,40$ & $15,25,35,45,55$ \\
\hline
\end{tabular}


The results for the set of $500 \mathrm{Nm}$, still air test configurations described in Table 4-1 are presented in Table 4-2, Table 4-3 and Table 4-4 below.

Table 4-2 A310 optimal altitude test results function of the cost index value

\begin{tabular}{|c|c|c|c|c|c|}
\hline \multirow{3}{*}{ CI } & \multirow{3}{*}{$\begin{array}{c}\text { Optimal } \\
\text { altitude } \\
\text { difference }\end{array}$} & \multicolumn{2}{|c|}{ Algorithm 1} & \multicolumn{2}{|c|}{ Algorithm 2} \\
\hline & & \multirow{2}{*}{$\begin{array}{l}\text { Number } \\
\text { of tests }\end{array}$} & \multirow[t]{2}{*}{$\%$} & \multirow{2}{*}{$\begin{array}{l}\text { Number } \\
\text { of tests }\end{array}$} & \multirow[t]{2}{*}{$\%$} \\
\hline & & & & & \\
\hline \multirow{4}{*}{0} & -1000 & & & 18 & 9.94 \\
\hline & 0 & 152 & 83.98 & 135 & 74.59 \\
\hline & 1000 & 26 & 14.36 & 25 & 13.81 \\
\hline & 2000 & 3 & 1.66 & 3 & 1.66 \\
\hline \multirow{3}{*}{15} & -1000 & & & 10 & 5.52 \\
\hline & 0 & 146 & 80.66 & 145 & 80.11 \\
\hline & 1000 & 35 & 19.34 & 26 & 14.36 \\
\hline \multirow{3}{*}{35} & -1000 & & & 10 & 5.52 \\
\hline & $\overline{0}$ & 144 & 79.56 & 127 & 70.17 \\
\hline & 1000 & 37 & 20.44 & 44 & 24.31 \\
\hline \multirow{4}{*}{50} & -1000 & & & 2 & 1.11 \\
\hline & 0 & 139 & 76.80 & 133 & 73.48 \\
\hline & 1000 & 35 & 19.34 & 39 & 21.55 \\
\hline & 2000 & 7 & 3.87 & 7 & 3.87 \\
\hline \multirow{4}{*}{100} & -1000 & 2 & 1.11 & & \\
\hline & 0 & 148 & 81.77 & 163 & 90.06 \\
\hline & 1000 & 22 & 12.15 & 18 & 9.94 \\
\hline & 2000 & 9 & 4.97 & & \\
\hline
\end{tabular}


Table 4-3 A310 performance results, function of the cost index value, as a difference between the algorithm computed values at the optimal altitudes computed using the algorithm and the PTT validation data

\begin{tabular}{|c|c|c|c|c|c|c|c|}
\hline \multirow{3}{*}{ Parameter } & \multirow{3}{*}{ CI } & \multicolumn{3}{|c|}{ Algorithm 1} & \multicolumn{3}{|c|}{ Algorithm 2} \\
\hline & & $\min$ & $\max$ & avg & $\min$ & $\max$ & avg \\
\hline & & $\%$ & $\%$ & $\%$ & $\%$ & $\%$ & $\%$ \\
\hline total cost & \multirow{3}{*}{0} & -0.68 & 0.00 & -0.07 & -0.56 & 0.00 & -0.07 \\
\hline fuel burn & & -0.68 & 0.00 & -0.07 & -0.56 & 0.00 & -0.07 \\
\hline flight time & & -1.18 & 0.00 & -0.04 & -0.90 & 0.98 & 0.04 \\
\hline total cost & \multirow{3}{*}{15} & -0.45 & 0.00 & -0.05 & -0.45 & 0.00 & -0.05 \\
\hline fuel burn & & -0.56 & 0.25 & -0.04 & -0.56 & 0.04 & -0.06 \\
\hline flight time & & -1.19 & 0.00 & -0.06 & -0.90 & 0.98 & -0.01 \\
\hline total cost & \multirow{3}{*}{35} & -0.44 & 0.00 & -0.05 & -0.36 & 0.00 & -0.05 \\
\hline fuel burn & & -0.78 & 0.25 & -0.06 & -0.56 & 0.66 & 0.00 \\
\hline flight time & & -1.18 & 0.52 & -0.03 & -1.96 & 0.97 & -0.19 \\
\hline total cost & \multirow{3}{*}{50} & -0.63 & 0.00 & -0.06 & -0.31 & 0.00 & -0.05 \\
\hline fuel burn & & -1.51 & 0.25 & -0.12 & -1.14 & 0.70 & 0.00 \\
\hline flight time & & -1.18 & 0.52 & 0.02 & -1.96 & 0.90 & -0.16 \\
\hline total cost & \multirow{3}{*}{100} & -0.32 & 0.00 & -0.03 & -0.19 & 0.00 & -0.01 \\
\hline fuel burn & & -1.60 & 0.56 & -0.12 & -0.54 & 0.00 & -0.03 \\
\hline flight time & & -0.41 & 0.52 & 0.03 & 0.00 & 0.00 & 0.00 \\
\hline
\end{tabular}


Table 4-4 A310 performance results, function of the cost index value, as the difference between the values computed using the algorithm and the PTT validation data, at the optimal altitude computed by the algorithm

\begin{tabular}{|c|c|c|c|c|c|c|c|}
\hline \multirow{3}{*}{ Parameter } & \multirow{3}{*}{ CI } & \multicolumn{3}{|c|}{ Algorithm 1} & \multicolumn{3}{|c|}{ Algorithm 2} \\
\hline & & $\min$ & $\max$ & avg & $\min$ & $\max$ & avg \\
\hline & & $\%$ & $\%$ & $\%$ & $\%$ & $\%$ & $\%$ \\
\hline total cost & \multirow{3}{*}{0} & -3.32 & -0.00 & -0.49 & -3.12 & 0.32 & -0.48 \\
\hline fuel burn & & -3.32 & -0.00 & -0.49 & -3.12 & 0.32 & -0.48 \\
\hline flight time & & -0.38 & 0.42 & $\begin{array}{c}-0.06 \\
\end{array}$ & 0.00 & 0.00 & 0.00 \\
\hline total cost & \multirow{3}{*}{15} & -2.66 & 0.02 & -0.42 & -2.46 & 0.31 & -0.37 \\
\hline fuel burn & & -3.32 & -0.00 & -0.51 & -3.12 & 0.37 & -0.46 \\
\hline flight time & & -0.37 & 0.42 & -0.07 & 0.00 & 0.00 & 0.00 \\
\hline total cost & \multirow{3}{*}{35} & -2.11 & 0.07 & -0.35 & -1.91 & 0.27 & $\begin{array}{l}-0.31 \\
\end{array}$ \\
\hline fuel burn & & -3.32 & -0.00 & -0.51 & -3.12 & 0.37 & -0.49 \\
\hline flight time & & -0.37 & 0.42 & -0.07 & 0.00 & 0.00 & 0.00 \\
\hline total cost & \multirow{3}{*}{50} & -1.84 & 0.10 & -0.31 & -1.64 & 0.20 & -0.28 \\
\hline fuel burn & & -3.32 & -0.00 & -0.51 & -3.12 & 0.32 & -0.50 \\
\hline flight time & & -0.37 & 0.42 & -0.07 & 0.00 & 0.00 & 0.00 \\
\hline total cost & \multirow{3}{*}{100} & -1.32 & 0.19 & -0.20 & -1.11 & 0.15 & $\overline{-0.18}$ \\
\hline fuel burn & & -3.32 & -0.02 & -0.50 & -3.12 & 0.32 & -0.47 \\
\hline flight time & & -0.35 & 0.42 & -0.01 & 0.00 & 0.00 & 0.00 \\
\hline
\end{tabular}


Table 4-2 presents an analysis of the optimal altitude differences between the values computed by each of the two developed algorithms, and the corresponding optimal altitude computed using the PTT validation data, as a function of the cost index values. Table 4-3 presents an analysis, for each of the two developed algorithms, of the minimal, maximal and average values of the relative difference between the flight time, fuel burn and total cost values computed by the algorithm, at the algorithm optimal altitude and at the optimal altitude computed using the PTT validation data, as a function of the cost index. Table 4-4 presents an analysis, for each of the two developed algorithms, of the minimal, maximal and average values of the relative difference between the flight time, fuel burn and total cost values computed by the algorithm and the values computed using the PTT validation data, at the algorithm optimal altitude, as a function of the cost index. A negative value of the optimal altitude difference is determined by an algorithm-computed optimal altitude situated lower than the corresponding optimal altitude determined using the PTT validation data. Similarly, a negative value of the total cost or fuel burn relative difference is produced by an algorithm computed value that is smaller than the corresponding value computed using the PTT validation data.

The performance results in Table 4-2 showed that for both algorithms, an important number of test cases, up to $23.2 \%$ for the first algorithm and $29.83 \%$ for the second algorithm, generated an optimal altitude that was situated from 1,000 ft below, to 2,000 ft above the corresponding optimal altitude computed using the PTT validation data. An analysis of the cost, fuel and flight time performance results, presented in Table 4-3 and Table 4-4, indicated that these altitude differences were mostly influenced by the fuel burn modeling.

The results in Table 4-3 show that the relative differences of the algorithm-computed total cost, evaluated at the optimal altitudes determined by the algorithm and the corresponding optimal altitude computed using the PTT validation data, range from $-0.63 \%$ to $0 \%$ for the total cost computed by algorithm 1 , and from $-0.56 \%$ to $0 \%$ for the algorithm 2 . Table $4-3$ also shows that the relative fuel burn differences, computed for the same conditions, range from $-1.51 \%$ to $0.56 \%$ for algorithm 1 , and from $-1.14 \%$ to $0.98 \%$ for algorithm 2 . 
The results in Table 4-4 show that the relative differences between the algorithm-computed total cost, and the total cost computed using the PTT validation data, evaluated at the optimal altitude computed by the algorithm, range from $-3.32 \%$ to $0.19 \%$ for the total cost computed by algorithm 1 , and from $-3.12 \%$ to $0.32 \%$ for the algorithm 2 . Table $4-4$ also shows that the relative fuel burn differences, computed for the same conditions, range from $-3.32 \%$ to $-0.02 \%$ for algorithm 1 , and from $-3.12 \%$ to $0.37 \%$ for algorithm 2 . It can be observed that a positive value of the relative fuel burn difference corresponding to the algorithm 2 means that the fuel burn value computed by the fuel burn algorithm, for an altitude and flight time, is larger than the fuel burn value computed by the PTT for the same altitude and flight time. This is consistent with the fact that the $c g$ variation with the fuel weight, and by consequence $g w$, is not monotonous. Therefore, the fuel burn rate computed by the algorithm may increase on certain gross weight domains.

The algorithm execution time statistics, for the initialization, intermediary, and optimal altitude module, respectively, are presented in Table 4-5, Table 4-6 and Table 4-7, below.

Table 4-5 A310 Initialization module execution time statistics

\begin{tabular}{|c|c|c|c|c|c|}
\hline \multicolumn{3}{|c|}{ Algorithm 1 } & \multicolumn{3}{c|}{ Algorithm 2 } \\
\hline min & max & average & min & max & average \\
time & time & time & time & time \\
\hline $\mathrm{s}$ & $\mathrm{s}$ & $\mathrm{s}$ & $\mathrm{s}$ & $\mathrm{s}$ & $\mathrm{s}$ \\
\hline 0.0052 & 0.5857 & 0.0112 & 0.0052 & 0.0948 & 0.0104 \\
\hline
\end{tabular}

As mentioned before, the initialization module is executed only once, before take-off, after the $z f g w, z f w c g$ and fuel weight values are set. For the set of tests presented in this thesis, the amount of time required for running the initialization module were measured to be between 0.0129 and 0.1026 seconds, with an average value of 0.0152 seconds. 
Table 4-6 A310 Intermediary module execution time statistics

\begin{tabular}{|c|c|c|c|c|c|c|}
\hline \multirow{2}{*}{$\begin{array}{c}\text { fuel weight } \\
\text { span }\end{array}$} & \multicolumn{3}{|c|}{ Algorithm 1 } & \multicolumn{3}{c|}{ Algorithm 2 } \\
\cline { 2 - 7 } & $\begin{array}{c}\text { min } \\
\text { time }\end{array}$ & max time & $\begin{array}{c}\text { average } \\
\text { time }\end{array}$ & $\begin{array}{c}\text { min } \\
\text { time }\end{array}$ & max time & $\begin{array}{c}\text { average } \\
\text { time }\end{array}$ \\
\hline $\mathrm{Kg}$ & $\mathrm{s}$ & $\mathrm{s}$ & $\mathrm{s}$ & $\mathrm{s}$ & $\mathrm{s}$ & $\mathrm{s}$ \\
\hline 15000 & 12.6178 & 37.962 & 17.8924 & 12.3575 & 36.9177 & 17.5526 \\
\hline 25000 & 18.7237 & 46.0777 & 22.7707 & 18.3396 & 44.9541 & 22.314 \\
\hline 35000 & 24.7152 & 67.0275 & 35.9109 & 24.2971 & 65.532 & 35.4261 \\
\hline 45000 & 34.4046 & 135.2796 & 50.4876 & 33.7307 & 132.9502 & 49.1502 \\
\hline 55000 & 47.2334 & 150.9742 & 64.9779 & 41.5122 & 148.2863 & 62.5959 \\
\hline
\end{tabular}

For a cruise maximal altitude range composed of 21 altitudes, and fuel weight spans between 15,000 and $55,000 \mathrm{Kg}$, corresponding to flight times between 3 and 12 hours, the maximal time required to generate the fuel burn look-up tables were situated between $38 \mathrm{sec}$ and 151 $\sec (2 \mathrm{~min}$ and $31 \mathrm{sec})$, with an average time value were situated between 18 and $65 \mathrm{sec}(1$ min and $5 \mathrm{sec}$ ). Consequently, upon changing the speed schedule or ISA_Dev values, the fuel burn data, and subsequently the optimal cruise altitude value, may not be available for a time period of more than $2 \mathrm{~min}$ and $30 \mathrm{sec}$.

Table 4-7 A310 Optimal altitude module execution time statistics

\begin{tabular}{|c|c|c|c|c|c|}
\hline \multicolumn{3}{|c|}{ Algorithm 1 } & \multicolumn{3}{c|}{ Algorithm 2 } \\
\hline $\begin{array}{c}\text { min } \\
\text { time }\end{array}$ & $\begin{array}{c}\text { max } \\
\text { time }\end{array}$ & $\begin{array}{c}\text { average } \\
\text { time }\end{array}$ & $\begin{array}{c}\text { min } \\
\text { time }\end{array}$ & $\begin{array}{c}\text { max } \\
\text { time }\end{array}$ & $\begin{array}{c}\text { average } \\
\text { time }\end{array}$ \\
\hline $\mathrm{s}$ & $\mathrm{s}$ & $\mathrm{s}$ & $\mathrm{s}$ & $\mathrm{s}$ & $\mathrm{s}$ \\
\hline 0.0129 & 0.1026 & 0.0152 & 0.0023 & 0.0542 & 0.0094 \\
\hline
\end{tabular}


The optimal altitude module time statistics, presented in Table 4-7, show that for still air conditions, and a cruise altitude range of 21 altitudes, the execution time were situated between $13 \mathrm{~ms}$ and $103 \mathrm{~ms}$, with an average value of $15 \mathrm{~ms}$. 


\subsection{The test results for Sukhoi RRJ}

A number of 43 still air test configurations, corresponding to a cruise segment of $500 \mathrm{Nm}$, were considered as described by the Table 4-8 below. They were chosen to cover the aircraft's range of IAS and Mach index speeds, $z f g w$, and fuel values.

Table 4-8 Description of the RRJ test configurations

\begin{tabular}{|c|c|c|c|}
\hline $\begin{array}{c}\text { IAS/Mach } \\
\text { Kts/- }\end{array}$ & $\begin{array}{c}\text { zfgw } \\
* 1,000 \mathrm{Kg}\end{array}$ & $\begin{array}{c}\text { zfwcg } \\
\text { \%MAC }\end{array}$ & $\begin{array}{c}\text { fuel } \\
* 1,000 \mathrm{Kg}\end{array}$ \\
\hline $240 / 0.74$ & 80 & $16,22,28,34,40$ & $15,25,35$ \\
\hline $240 / 0.74$ & 90 & 16 & 15,25 \\
\hline $240 / 0.74$ & 90 & 28 & $15,25,35$ \\
\hline $280 / 0.78$ & 80 & $16,28,34,40$ & $15,25,35,45,55$ \\
\hline $280 / 0.78$ & 80 & 22 & $25,35,45,55$ \\
\hline $280 / 0.78$ & 90 & $16,22,28,34,40$ & $15,25,35,45,55$ \\
\hline $280 / 0.78$ & 100 & 16 & $15,25,35$ \\
\hline $280 / 0.78$ & 100 & 22 & $15,25,35,55$ \\
\hline $280 / 0.78$ & 100 & 28 & $25,35,45,55$ \\
\hline $280 / 0.78$ & 100 & 34,40 & $15,25,35,45,55$ \\
\hline $320 / 0.82$ & 80 & $16,22,28,34$ & $15,25,35,45,55$ \\
\hline $320 / 0.82$ & 80 & 40 & $15,25,35,45$ \\
\hline $320 / 0.82$ & 90 & $16,28,34$ & $15,25,35,45,55$ \\
\hline $320 / 0.82$ & 90 & 22 & $15,25,35,45$ \\
\hline $320 / 0.82$ & 90 & 40 & $15,35,45,55$ \\
\hline $320 / 0.82$ & 100 & $16,22,28,34,40$ & $15,25,35,45$ \\
\hline $340 / 0.84$ & 90 & 16 & $15,25,35,45,55$ \\
\hline $340 / 0.84$ & 90 & $22,28,34,40$ & \\
\hline
\end{tabular}


The results for the set of $500 \mathrm{Nm}$, still air test configurations described in Table 4-8 are presented in Table 4-9, Table 4-10 and Table 4-11 below.

Table 4-9 RRJ optimal altitude test results function of the cost index value

\begin{tabular}{|c|c|c|c|c|c|}
\hline \multirow{3}{*}{ CI } & \multirow{3}{*}{ 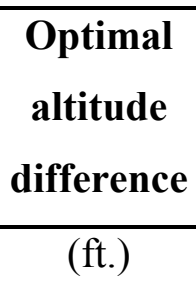 } & \multicolumn{2}{|c|}{ Algorithm 1} & \multicolumn{2}{|c|}{ Algorithm 2} \\
\hline & & \multirow{2}{*}{$\begin{array}{l}\text { Number } \\
\text { of tests }\end{array}$} & \multirow[t]{2}{*}{$\%$} & \multirow{2}{*}{$\begin{array}{l}\text { Number } \\
\text { of tests }\end{array}$} & \multirow[t]{2}{*}{$\%$} \\
\hline & & & & & \\
\hline \multirow{3}{*}{0} & 0 & 33 & 76.74 & 33 & 76.74 \\
\hline & 1000 & 1 & 2.33 & 1 & 2.33 \\
\hline & 2000 & 9 & 20.93 & 9 & 20.93 \\
\hline \multirow{3}{*}{15} & 0 & 33 & 76.74 & 33 & 76.74 \\
\hline & 1000 & 1 & 2.33 & 1 & 2.33 \\
\hline & 2000 & 9 & 20.93 & 9 & 20.93 \\
\hline \multirow{4}{*}{35} & 0 & 32 & 74.42 & 33 & 76.74 \\
\hline & 1000 & 1 & 2.33 & 1 & 2.33 \\
\hline & 2000 & 9 & 20.93 & 9 & 20.93 \\
\hline & 6000 & 1 & 2.33 & & \\
\hline \multirow{4}{*}{50} & 0 & 32 & 74.42 & 33 & 76.74 \\
\hline & 1000 & 1 & 2.33 & 1 & 2.33 \\
\hline & 2000 & 9 & 20.93 & 9 & 20.93 \\
\hline & 6000 & 1 & 2.33 & & \\
\hline \multirow{5}{*}{100} & 0 & 32 & 74.42 & 33 & 76.74 \\
\hline & 1000 & 1 & 2.33 & 1 & 2.33 \\
\hline & 2000 & 7 & 16.28 & 7 & 16.28 \\
\hline & 3000 & 2 & 4.65 & 2 & 4.65 \\
\hline & 6000 & 1 & 2.33 & & \\
\hline
\end{tabular}


Table 4-10 RRJ performance results, function of the cost index value, as a difference between the algorithm computed values at the optimal altitudes computed using the algorithm and the PTT validation data

\begin{tabular}{|c|c|c|c|c|c|c|c|}
\hline \multirow{3}{*}{ Parameter } & \multirow{3}{*}{ CI } & \multicolumn{3}{|c|}{ Algorithm 1} & \multicolumn{3}{|c|}{ Algorithm 2} \\
\hline & & $\min$ & $\max$ & avg & $\min$ & $\max$ & avg \\
\hline & & $\%$ & $\%$ & $\%$ & $\%$ & $\%$ & $\%$ \\
\hline total cost & \multirow{3}{*}{0} & -1.15 & 0 & -0.18 & -1.15 & 0 & -0.18 \\
\hline fuel burn & & -1.15 & 0 & -0.18 & -1.15 & 0 & -0.18 \\
\hline flight time & & 0 & 0 & 0 & 0 & 0 & 0 \\
\hline total cost & \multirow{3}{*}{15} & $\begin{array}{c}-0.72 \\
\end{array}$ & $\overline{0}$ & -0.11 & -0.72 & 0 & -0.11 \\
\hline fuel burn & & -1.15 & 0 & -0.18 & -1.15 & 0 & -0.18 \\
\hline flight time & & 0 & 0 & 0 & 0 & 0 & 0 \\
\hline total cost & \multirow{3}{*}{35} & $\begin{array}{l}-5.84 \\
\end{array}$ & 0 & -0.21 & -0.48 & 0 & -0.08 \\
\hline fuel burn & & -13.63 & 0 & -0.50 & -1.15 & 0 & -0.18 \\
\hline flight time & & 0 & 0.01 & 0 & 0 & 0 & 0 \\
\hline total cost & \multirow{3}{*}{50} & -4.69 & 0 & -0.17 & -0.39 & 0 & -0.06 \\
\hline fuel burn & & -13.63 & 0 & -0.50 & -1.15 & 0 & -0.18 \\
\hline flight time & & 0 & 0.01 & 0 & 0 & 0 & 0 \\
\hline total cost & \multirow{3}{*}{100} & -2.83 & 0 & -0.11 & -0.34 & 0 & -0.04 \\
\hline fuel burn & & -13.63 & 0 & -0.60 & -3.23 & 0 & -0.28 \\
\hline flight time & & 0 & 0.52 & 0.02 & 0 & 0.55 & 0.03 \\
\hline
\end{tabular}


Table 4-11 RRJ performance results, function of the cost index value, as the difference between the values computed using the algorithm and the PTT validation data, at the optimal altitude computed by the algorithm

\begin{tabular}{|c|c|c|c|c|c|c|c|}
\hline \multirow{3}{*}{ Parameter } & \multirow{3}{*}{ CI } & \multicolumn{3}{|c|}{ Algorithm 1} & \multicolumn{3}{|c|}{ Algorithm 2} \\
\hline & & $\min$ & $\max$ & avg & $\min$ & $\max$ & $\operatorname{avg}$ \\
\hline & & $\%$ & $\%$ & $\%$ & $\%$ & $\%$ & $\%$ \\
\hline total cost & \multirow{3}{*}{0} & -4.09 & -0.59 & -2.67 & -3.25 & -0.47 & -2.67 \\
\hline fuel burn & & -4.09 & -0.59 & -2.67 & -3.25 & -0.47 & -2.67 \\
\hline flight time & & -1.35 & 1.58 & 0.00 & 0.00 & 0.00 & 0.00 \\
\hline total cost & \multirow{3}{*}{15} & -3.08 & -0.32 & -1.68 & -1.98 & -0.31 & -1.68 \\
\hline fuel burn & & -4.09 & -0.59 & -2.67 & -3.25 & -0.47 & -2.67 \\
\hline flight time & & -1.35 & 1.58 & 0.00 & 0.00 & 0.00 & 0.00 \\
\hline total cost & \multirow{3}{*}{35} & -2.51 & 0.34 & -1.13 & -1.33 & -0.05 & -1.10 \\
\hline fuel burn & & -4.09 & -0.59 & -2.67 & -3.25 & -0.12 & -2.60 \\
\hline flight time & & -1.35 & 1.58 & 0.00 & 0.00 & 0.00 & 0.00 \\
\hline total cost & \multirow{3}{*}{50} & -2.28 & 0.59 & -0.90 & -1.07 & -0.04 & -0.88 \\
\hline fuel burn & & -4.09 & -0.59 & -2.67 & -3.25 & -0.12 & -2.60 \\
\hline flight time & & -1.35 & 1.58 & 0.00 & 0.00 & 0.00 & 0.00 \\
\hline total cost & \multirow{3}{*}{100} & -1.91 & 0.99 & -0.53 & -0.65 & -0.02 & -0.52 \\
\hline fuel burn & & -4.09 & -0.27 & -2.63 & -3.25 & -0.12 & -2.57 \\
\hline flight time & & -1.35 & 1.58 & 0.00 & 0.00 & 0.00 & 0.00 \\
\hline
\end{tabular}


Table 4-9 presents an analysis of the optimal altitude differences between the values computed by each of the two developed algorithms, and the corresponding optimal altitude computed using the PTT validation data, as a function of the cost index values. Table 4-10 presents an analysis, for each of the two developed algorithms, of the minimal, maximal and average values of the relative difference between the flight time, fuel burn and total cost values computed by the algorithm, at the algorithm optimal altitude and at the optimal altitude computed using the PTT validation data, as a function of the cost index. Table 4-11 presents an analysis, for each of the two developed algorithms, of the minimal, maximal and average values of the relative difference between the flight time, fuel burn and total cost values computed by the algorithm and the values computed using the PTT validation data, at the algorithm optimal altitude, as a function of the cost index. A negative value of the optimal altitude difference is determined by an algorithm-computed optimal altitude situated lower than the corresponding optimal altitude determined using the PTT validation data. Similarly, a negative value of the total cost or fuel burn relative difference is produced by an algorithm computed value that is smaller than the corresponding value computed using the PTT validation data.

The performance results in Table 4-9 showed that for both algorithms, an important number of test cases, up to $23.2 \%$ for the first algorithm and $29.83 \%$ for the second algorithm, generated an optimal altitude that was situated from 1,000 ft below to 2,000 ft above the corresponding optimal altitude computed using the PTT validation data. An analysis of the cost, fuel and flight time performance results, presented in Table 4-10 and Table 4-11, indicated that these altitude differences were mostly influenced by the fuel burn modeling.

The results in Table 4-10 show that the relative differences of the algorithm-computed total cost, evaluated at the optimal altitudes determined by the algorithm and the corresponding optimal altitude computed using the PTT validation data, range from $-5.84 \%$ to $0 \%$ for the total cost computed by algorithm 1 , and from $-1.15 \%$ to $0 \%$ for the algorithm 2 . Table $4-10$ also shows that the relative fuel burn differences, computed for the same conditions, range from $-13.63 \%$ to $0 \%$ for algorithm 1 , and from $-3.23 \%$ to $0 \%$ for algorithm 2 . 
One important note relative to the Algorithm 1 flight time differences presented in the Table 4-10, for cost index values of 0 and 15: it can be observed that the min, max and average values are 0. Following a detailed investigation, it was determined that this is due to the fact that both FMS and algorithm determined optimal altitudes were situated at or above $36000 \mathrm{ft}$, in stratosphere, where the value of the speed of sound is constant with the altitude variation. Therefore the corresponding ground speed and segment flight time are constant with altitude variation.

The results in Table 4-11 show that the relative differences between the algorithm-computed total cost, and the total cost computed using the PTT validation data, evaluated at the optimal altitude computed by the algorithm, range from $-4.09 \%$ to $0.99 \%$ for the total cost computed by algorithm 1 , and from $-3.25 \%$ to $-0.02 \%$ for the algorithm 2 . Table $4-11$ also shows that the relative fuel burn differences, computed for the same conditions, range from $-4.09 \%$ to $-0.27 \%$ for algorithm 1 , and from $-3.25 \%$ to $-0.12 \%$ for algorithm 2 . It can be observed that the relative fuel burn difference corresponding to the algorithm 2 are always negative. This means that the fuel burn value computed by the fuel burn algorithm, for an altitude and flight time, is smaller than the fuel burn value computed by the PTT for the same altitude and flight time. This is consistent with the fact that for the $c g$ independent model, the fuel burn rate variation with the fuel weight, and by consequence $g w$, is monotonous.

The algorithm execution time statistics, for the initialization, intermediary, and optimal altitude module, respectively, are presented in Table 4-12, Table 4-13 and Table 4-14, below.

Table 4-12 RRJ Initialization module execution time statistics

\begin{tabular}{|c|c|c|c|c|c|}
\hline \multicolumn{3}{|c|}{ Algorithm 1 } & \multicolumn{3}{c|}{ Algorithm 2 } \\
\hline $\begin{array}{c}\text { min } \\
\text { time }\end{array}$ & $\begin{array}{c}\text { max } \\
\text { time }\end{array}$ & $\begin{array}{c}\text { average } \\
\text { time }\end{array}$ & $\begin{array}{c}\text { min } \\
\text { time }\end{array}$ & $\begin{array}{c}\text { max } \\
\text { time }\end{array}$ & $\begin{array}{c}\text { average } \\
\text { time }\end{array}$ \\
\hline $\mathrm{s}$ & $\mathrm{s}$ & $\mathrm{s}$ & $\mathrm{s}$ & $\mathrm{s}$ & $\mathrm{s}$ \\
\hline 0.00008 & 0.0001 & 0.00009 & 0.00008 & 0.0014 & 0.00009 \\
\hline
\end{tabular}


For RRJ performance model and the set of tests presented in this thesis, the amount of time required for running the initialization module were measured to be less than $1.5 \mathrm{~ms}$, with an average value of $0.09 \mathrm{~ms}$.

Table 4-13 RRJ Intermediary module execution time statistics

\begin{tabular}{|c|c|c|c|c|c|c|}
\hline \multirow{2}{*}{$\begin{array}{c}\text { fuel weight } \\
\text { span }\end{array}$} & \multicolumn{3}{|c|}{ Algorithm 1 } & \multicolumn{3}{c|}{ Algorithm 2 } \\
\cline { 2 - 7 } & $\begin{array}{c}\text { min } \\
\text { time }\end{array}$ & max time & $\begin{array}{c}\text { average } \\
\text { time }\end{array}$ & $\begin{array}{c}\text { min } \\
\text { time }\end{array}$ & max time & $\begin{array}{c}\text { average } \\
\text { time }\end{array}$ \\
\hline $\mathrm{Kg}$ & $\mathrm{s}$ & $\mathrm{s}$ & $\mathrm{s}$ & $\mathrm{s}$ & $\mathrm{s}$ & $\mathrm{s}$ \\
\hline 7000 & 3.5886 & 47.7753 & 10.7782 & 3.6070 & 48.3110 & 11.6924 \\
\hline 8000 & 4.0318 & 48.4457 & 4.5235 & 4.0409 & 48.4411 & 4.7548 \\
\hline 9000 & 4.6098 & 49.1462 & 10.2846 & 4.5548 & 49.7206 & 13.2245 \\
\hline 10000 & 5.0561 & 49.5312 & 15.2343 & 5.0614 & 50.2168 & 16.6336 \\
\hline
\end{tabular}

For a cruise maximal altitude range composed of 24 altitudes, and fuel weight spans between 7,000 and $10,000 \mathrm{Kg}$, the maximal time required to generate the fuel burn look-up tables were situated between $48 \mathrm{sec}$ and $51 \mathrm{sec}$, with an average time value situated between 4.6 and $16.7 \mathrm{sec}$. Consequently, upon changing the speed schedule or ISA_Dev values, the fuel burn data, and subsequently the optimal cruise altitude value, may not be available for a time period of more than $50 \mathrm{sec}$.

Table 4-14 RRJ Optimal altitude module execution time statistics

\begin{tabular}{|c|c|c|c|c|c|}
\hline \multicolumn{3}{|c|}{ Algorithm 1 } & \multicolumn{3}{c|}{ Algorithm 2 } \\
\hline $\begin{array}{c}\text { min } \\
\text { time }\end{array}$ & $\begin{array}{c}\text { max } \\
\text { time }\end{array}$ & $\begin{array}{c}\text { average } \\
\text { time }\end{array}$ & $\begin{array}{c}\text { min } \\
\text { time }\end{array}$ & $\begin{array}{c}\text { max } \\
\text { time }\end{array}$ & $\begin{array}{c}\text { average } \\
\text { time }\end{array}$ \\
\hline $\mathrm{s}$ & $\mathrm{s}$ & $\mathrm{s}$ & $\mathrm{s}$ & $\mathrm{s}$ & $\mathrm{s}$ \\
\hline 0.0154 & 0.0220 & 0.0163 & 0.0065 & 0.1070 & 0.0126 \\
\hline
\end{tabular}


The optimal altitude module time statistics, presented in Table 4-14, show that for still air conditions, and a maximal cruise altitude range of 24 altitudes, the execution time were situated between $15.4 \mathrm{~ms}$ and $22 \mathrm{~ms}$, with an average value of $16.3 \mathrm{~ms}$. 


\subsection{The test results for Lockheed L1011}

A number of 27 still air test configurations were considered, as described by the Table 4-15 below. They correspond to a cruise distance of $399.59 \mathrm{Nm}$. These configurations were chosen to cover the aircraft's range of IAS and Mach index speeds, zfgw, and fuel values. As mentioned before, the objective of the validation was to compare the algorithm fuel burn predictions with those computed by the PTT and the Flightsim.

The fuel burn difference values are presented as percentage of the fuel burn value extracted from the Flightsim recorded data. A positive value represents an algorithm / PTT predicted value that is larger than that corresponding to the Flightsim.

It can be observed that for all test cases the fuel burn differences between the algorithm and Flightsim values ranged from $1.89 \%$ to $4.52 \%$, whereas the difference between the PTT and Flightsim values ranged from $-1.34 \%$ to $6.59 \%$ of the corresponding Flightsim value. Considering the fact that the Flightsim computes the fuel burn in real time, its fuel burn value should provide the closest approximation of the integral of the fuel burn rate, and is considered the most accurate. By consequence, a negative value of the relative difference between the PTT and Flightsim computed fuel burn corresponds to a PTT value that is lower than the value of the integral of the fuel burn rate. However, the L1011 model is not cgdependent and its $f b r$ variation with the $g w$ is monotonous. Therefore, a PTT fuel burn value that is lower that the Flightsim' suggests that the algorithm that considers a constant fuel burn rate on each cruise sub-segment may predict fuel burn values that are smaller than the actual ones. More, for the majority of cases for which the PTT fuel burn is larger than the one computed by the Flightsim, the value corresponding to the new proposed fuel burn algorithm is closer to that of the Flightsim than the PTT value, therefore more accurate. 
Table 4-15 L1011 tests description and fuel burn results

\begin{tabular}{|c|c|c|c|c|c|c|}
\hline \multirow{2}{*}{$\begin{array}{c}\text { Speed } \\
\text { schedule } \\
(\text { Mach/IAS) }\end{array}$} & \multirow[b]{2}{*}{ ZFGW } & \multirow{2}{*}{$\begin{array}{c}\text { Fuel } \\
\text { weight }\end{array}$} & \multirow{2}{*}{$\begin{array}{c}\text { CRUISE } \\
\text { ALT }\end{array}$} & \multirow{2}{*}{$\begin{array}{c}\text { Flight } \\
\text { Time } \\
\text { (FMS) }\end{array}$} & \multicolumn{2}{|c|}{ Fuel Burn differences } \\
\hline & & & & & $\begin{array}{c}\text { FMS - } \\
\text { Flightsim }\end{array}$ & $\begin{array}{c}\text { ALG - } \\
\text { Flightsim }\end{array}$ \\
\hline - / Kts. & $\begin{array}{c}* 1000 \\
\mathrm{Kg}\end{array}$ & $\begin{array}{c}* 1000 \\
\mathrm{Kg}\end{array}$ & $\mathrm{ft}$ & $\mathrm{h}$ & $\%$ & $\%$ \\
\hline \multirow{9}{*}{$0.78 / 280$} & \multirow{3}{*}{117.3} & 29 & 38000 & 0.8920 & 6.39 & 4.52 \\
\hline & & 48.36 & 36000 & 0.8920 & 4.52 & 3.68 \\
\hline & & 72.5 & 34000 & 0.8840 & 3.24 & 2.40 \\
\hline & \multirow{3}{*}{140} & 22.2 & 36000 & 0.8920 & 0.20 & 3.86 \\
\hline & & 37 & 34000 & 0.8840 & -0.51 & 3.07 \\
\hline & & 55.5 & 33000 & 0.8800 & -0.35 & 2.72 \\
\hline & \multirow{3}{*}{150} & 19.2 & 36000 & 0.8920 & -0.37 & 3.23 \\
\hline & & 32 & 34000 & 0.8840 & -0.33 & 3.21 \\
\hline & & 48 & 33000 & 0.8800 & -0.62 & 2.61 \\
\hline \multirow{9}{*}{$0.80 / 300$} & \multirow{3}{*}{117.3} & 29 & 40000 & 0.8720 & 0.02 & 3.80 \\
\hline & & 48.36 & 36000 & 0.8720 & -0.33 & 3.57 \\
\hline & & 72.5 & 34000 & 0.8640 & -1.34 & 2.39 \\
\hline & \multirow{3}{*}{140} & 22.2 & 38000 & 0.8720 & 4.91 & 3.19 \\
\hline & & 37 & 36000 & 0.8720 & -1.09 & 2.68 \\
\hline & & 55.5 & 34000 & 0.8640 & 2.71 & 2.12 \\
\hline & \multirow{3}{*}{150} & 19.2 & 36000 & 0.8720 & 3.76 & 3.18 \\
\hline & & 32 & 34000 & 0.8640 & -0.63 & 3.21 \\
\hline & & 48 & 34000 & 0.8640 & 2.38 & 2.06 \\
\hline \multirow{9}{*}{$0.82 / 320$} & \multirow{3}{*}{117.3} & 29 & 40000 & 0.8480 & 6.59 & 3.49 \\
\hline & & 48.36 & 38000 & 0.8480 & -0.42 & 2.97 \\
\hline & & 72.5 & 34000 & 0.8400 & -1.50 & 1.94 \\
\hline & \multirow{3}{*}{140} & 22.2 & 38000 & 0.8480 & 4.99 & 2.97 \\
\hline & & 37 & 36000 & 0.8480 & 3.22 & 2.34 \\
\hline & & 55.5 & 34000 & 0.8400 & -1.48 & 1.89 \\
\hline & \multirow{3}{*}{150} & 19.2 & 36000 & 0.8480 & -0.85 & 2.75 \\
\hline & & 32 & 36000 & 0.8480 & -1.01 & 2.40 \\
\hline & & 48 & 34000 & 0.8400 & -1.37 & 1.96 \\
\hline
\end{tabular}




\section{CONCLUSIONS}

The algorithm described in this thesis was implemented for a number of three aircraft models, Airbus A310 which is $c g$ dependent, Locheed L1011, and Sukhoi RRJ, which are not cg dependent.

For the A310 and RRJ aircraft models, two versions of the algorithm were used for validation, the original version of the algorithm proposed in this thesis - that performs all the computations required to determine the optimal altitude, and a modified version - that uses the cruise altitude range and corresponding flight times, computed by the PTT. The modified version allowed for a better analyze of the differences between the fuel burn model proposed in this thesis and that used by the PTT. The test scenarios investigated algorithm performances, in still-air conditions, for an optimization distance of $500 \mathrm{Nm}$ and five cost index values $(0,15,35,50$ and 100). This approach is consistent with the fact that the wind conditions' influence on the fuel burn and total cost are produced through the changes induced in the value of the cruise segment's flight time only. Therefore, the still air scenarios allow for a good and accurate characterization of the fuel burn and optimal altitude algorithms' performances.

The test results showed that, depending on the cost index value, for up to $83 \%$ of A310 and $76 \%$ of RRJ test cases the optimal altitude computed by the algorithm was identical to that computed using the PTT validation data. Also, for up to $23 \%$ of the test cases the optimal altitudes were situated in a range of $2,000 \mathrm{ft}$ from the values computed using the PTT validation data. It is interesting to note that for the algorithm version that uses the PTT computed flight times and A310 model, depending on the cost index value, the percentage corresponding to identical values of optimal altitude rose up to $90 \%$, while the percentage

corresponding to optimal altitude differences also rose up to $30 \%$. For the RRJ model the percentages remained virtually unchanged. 
The test results for the A310 model, for the algorithm version that uses the PTT computed flight times, also showed that for identical altitudes and flight times, the values of the fuel burn computed by the algorithm were smaller for some test cases, and larger for other test cases, than the values computed by the PTT. This is consistent with the fact that the $c g$ variation with the fuel weight, and by consequence $g w$, is not monotonous. Therefore, the fuel burn rate computed by the algorithm may decrease on certain gross weight domains and increase on others. Also, the results of the L1011 tests performed on the Algorithm/PTT/Flightsim 9.1 platform indicated that the fuel burns predicted by the algorithm were closer to the values extracted from the Flightsim recordings, which are considered a close approximation of the fuel burn rate integral, than the values determined by the PTT. This suggests that the fuel burn model implemented by the algorithm is better than the model assuming constant fuel burn rates.

The analysis of the execution times of each of the main modules implementing the optimal cruise altitude algorithm suggests that the algorithm can successfully observe the requirements imposed by a real-time environment. The execution times for the initialization module are very small compared with the time between the FMS configuration and aircraft take-off, which is usually in the range of 15 to 30 minutes.

The intermediary module execution times were found to reach up to $150 \mathrm{sec}$ for the $\mathrm{cg}$ dependent, and $51 \mathrm{sec}$ for the cg-independent model. The delays caused by the fuel burn look-up tables generation, upon a change of speed schedule or ISA_Dev values, are not frequent and could be regarded as an algorithm limitation. A table generation and an update policy adapted to the aircraft's performances and selected optimization distance, in conjunction with an appropriate minimal cruise altitude selection, could provide an important reduction of the fuel burn look-up tables generation time.

The maximum response time of the optimal altitude module was determined to be of $103 \mathrm{~ms}$. Considering that the optimal cruise altitude value is computed or updated at time intervals of 
no less than one minute, similar to other FMS data, we can conclude that the optimal altitude module can successfully meet the optimal altitude computation and update time constraints.

In conclusion, the fuel burn algorithm presented in this thesis provides two important features: Firstly, the value of the fuel burn considers the continuous variation of the fuel burn rate with time, due to the variation of the fuel weight, thus it's more accurate than that considering constant fuel burn rates on sub-segments of $50 \mathrm{Nm}$. Secondly, it would no longer require the decomposition of a cruise segment in smaller sub-segments, thus reducing the volume of computations. This, in turn, opens the possibility for computing fuel burn values for cruise flights spanning multiple segments, at once, using the corresponding total flight time. 



\section{RECOMMENDATIONS}

The analysis of the results presented in this thesis identified a number of directions, and tasks, that could contribute to extending the characterization of algorithm's performances, and/or augment its capabilities.

The first recommendation addresses the generation of the FMS validation data, as it was the principal factor limiting the number of test scenarios, and aircraft models, covered in this thesis. It refers to identifying, or implementing a method that automates the process of generation, and collection, of CMA 9000 FMS validation data, in collaboration with CMC Electronics - Esterline. Subsequently, extending the number of test scenarios, both for still air and constant wind conditions, would allow a more detailed characterization of the algorithm's performances and its advantages.

Other work may also include optimal cruise altitude algorithm improvement, with the implementation of variable wind (wind blending) scenarios processing capabilities, and the consideration of the costs, and fuel burns, associated with the climbs and descents imposed by the cruise altitude change.

The optimal cruise altitude algorithm can be easily adapted for scenarios where the optimization distance corresponds to a series of consecutive, independent, segments flown at the same speed schedule and ISA_Dev values.

Finally, we propose the implementation of the fuel burn computation algorithm, presented in this thesis, for all cruise, constant speed, level flight computations performed by the FMS. 



\section{LIST OF BIBLIOGRAPHIC REFERENCES}

[1] Liden, S., 1994. “The evolution of Flight Management Systems”, Digital Avionics Systems Conference, 1994. 13 ${ }^{\text {th }}$ DASC., AIAA/IEEE, vol., no., pp.157-169, 30 Oct-3 Nov 1994. Online.

$<$ http://ieeexplore.ieee.org/stamp/stamp.jsp?tp=\&arnumber=369487\&isnumber $=8448>$. Retrieved on April 13, 2011

[2] Herndon, A.A.; Cramer, M.; Nicholson, T., 2009. "Analysis of advanced flight management systems (FMS), flight management computer (FMC) field observations, trials; lateral and vertical path integration" Digital Avionics Systems Conference, 2009. DASC '09. IEEE/AIAA 28th, vol., no., pp.1.C.2-1-1.C.2-16, 23-29 Oct. 2009. Online. $<$ http://ieeexplore.iee.org/stamp/stamp.jsp?tp $=$ \&arnumber $=5347572$ \&isnumber $=5347$ 412>. Retrieved on April 10, 2011

[3] Liden, S., 1992. "Optimum cruise profiles in the presence of winds," Digital Avionics Systems Conference, 1992. Proceedings., IEEE/AIAA 11th , vol., no., pp.254-261, 5-8 Oct 1992. Online.

$<\mathrm{http}$ ://ieeexplore.ieee.org/stamp/stamp.jsp?tp=\&arnumber=282147\&isnumber $=6983>$. Retrieved on May 7, 2010

[4] Liden, S., 1992. "Optimum 4D guidance for long flights," Digital Avionics Systems Conference, 1992. Proceedings., IEEE/AIAA 11th, vol., no., pp.262-267, 5-8 Oct 1992. Online.

$<\mathrm{http}$ ://ieeexplore.ieee.org/stamp/stamp.jsp?tp=\&arnumber=282146\&isnumber $=6983 \mathrm{ht}$ tp://ieeexplore.ieee.org/stamp/stamp.jsp?tp=\&arnumber=282146\&isnumber $=6983>$. Retrieved on May 22, 2010

[5] Liden, S., 1985. "Practical Considerations in Optimal Flight Management Computations," American Control Conference, 1985 , vol., no., pp.675-681, 19-21 June 1985. Online. $<\mathrm{http}$ ://ieeexplore.ieee.org/stamp/stamp.jsp?tp=\&arnumber $=4788700 \&$ isnumber $=4788$ 561>. Retrieved on May 22, 2010

[6] Shufan Wu; Yongzhang Shen; , 1993. "Studies on the flight performance optimization of commercial aircrafts," TENCON '93. Proceedings. Computer, Communication, Control and Power Engineering.1993 IEEE Region 10 Conference on, vol., no.0, pp.139-145 vol.4, 19-21 Oct 1993. Online.

$<\mathrm{http}$ ://ieeexplore.ieee.org/stamp/stamp.jsp?tp=\&arnumber=320453\&isnumber $=7692>$. Retrieved on April 10, 2011

[7] Asselin, M., 1997, “AIAA Education Series: An Introduction to Aircraft Performance”, Reston, Virginia, USA: American Institute of Aeronautics and Astronautics, Inc.,339 p. 
[8] Botez, R., 2006, GPA-745: Introduction à l'avionique: notes de cours GPA-745. Bachelor and Master's engineering programs. Montreal: Ecole de Technologie Superieure, multiple pagination, $394 \mathrm{p}$.

[9] Botez, R., 2006, GPA-745: Introduction à 1'avionique: notes de laboratoire GPA-745. Bachelor and Master's engineering programs. Montreal: Ecole de Technologie Superieure, multiple pagination, $99 \mathrm{p}$.

[10] Federal Aviation Administration, 2007, "Aircraft Weight and Balance Handbook", Online. 97p. <http://www.faa.gov/library/manuals/aircraft/media/FAA-H-80831A.pdf $>$. Retrieved on November 10, 2010

[11] Butcher, J. C., 1987, “The numerical analysis of ordinary differential equations: RungeKutta and general linear methods", New York, USA: Wiley-Interscience, 512 pages. 
